\title{
System Noise Assessment and the Potential for a Low Noise Hybrid Wing Body Aircraft with Open Rotor Propulsion
}

\author{
Russell H. Thomas ${ }^{1}$, Casey L. Burley ${ }^{2}$, Leonard V. Lopes ${ }^{3}$, Christopher J. Bahr ${ }^{4}$, Frank H. Gern ${ }^{5}$ \\ NASA Langley Research Center, Hampton, VA 23681 USA \\ and \\ Dale E. Van Zante ${ }^{6}$ \\ NASA Glenn Research Center, Cleveland, OH 44135 USA
}

\begin{abstract}
An aircraft system noise assessment was conducted for a hybrid wing body freighter aircraft concept configured with three open rotor engines. The primary objective of the study was to determine the aircraft system level noise given the significant impact of installation effects including shielding the open rotor noise by the airframe. The aircraft was designed to carry a payload of $100,000 \mathrm{lbs}$ on a 6,500 nautical mile mission. An experimental database was used to establish the propulsion airframe aeroacoustic installation effects including those from shielding by the airframe planform, interactions with the control surfaces, and additional noise reduction technologies. A second objective of the study applied the impacts of projected low noise airframe technology and a projection of advanced low noise rotors appropriate for the NASA N+2 2025 timeframe. With the projection of low noise rotors and installation effects, the aircraft system level was 26.0 EPNLdB below Stage 4 level with the engine installed at $\mathbf{1 . 0}$ rotor diameters upstream of the trailing edge. Moving the engine to 1.5 rotor diameters brought the system level noise to 30.8 EPNLdB below Stage 4 . At these locations on the airframe, the integrated level of installation effects including shielding can be as much as 20 EPNLdB cumulative in addition to lower engine source noise from advanced low noise rotors. And finally, an additional set of technology effects were identified and the potential impact at the system level was estimated for noise only without assessing the impact on aircraft performance. If these additional effects were to be included it is estimated that the potential aircraft system noise could reach as low as 38.0 EPNLdB cumulative below Stage 4 .
\end{abstract}

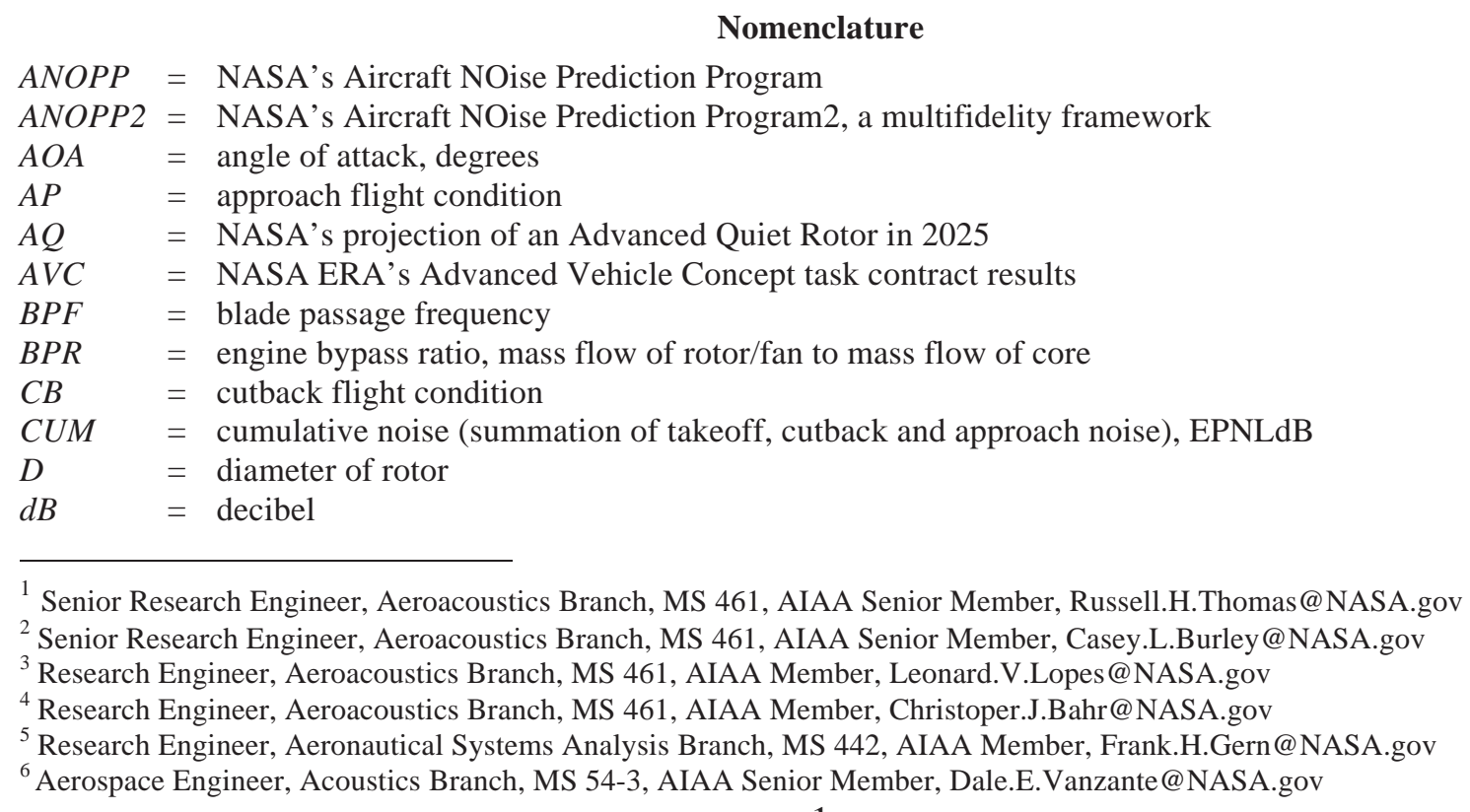




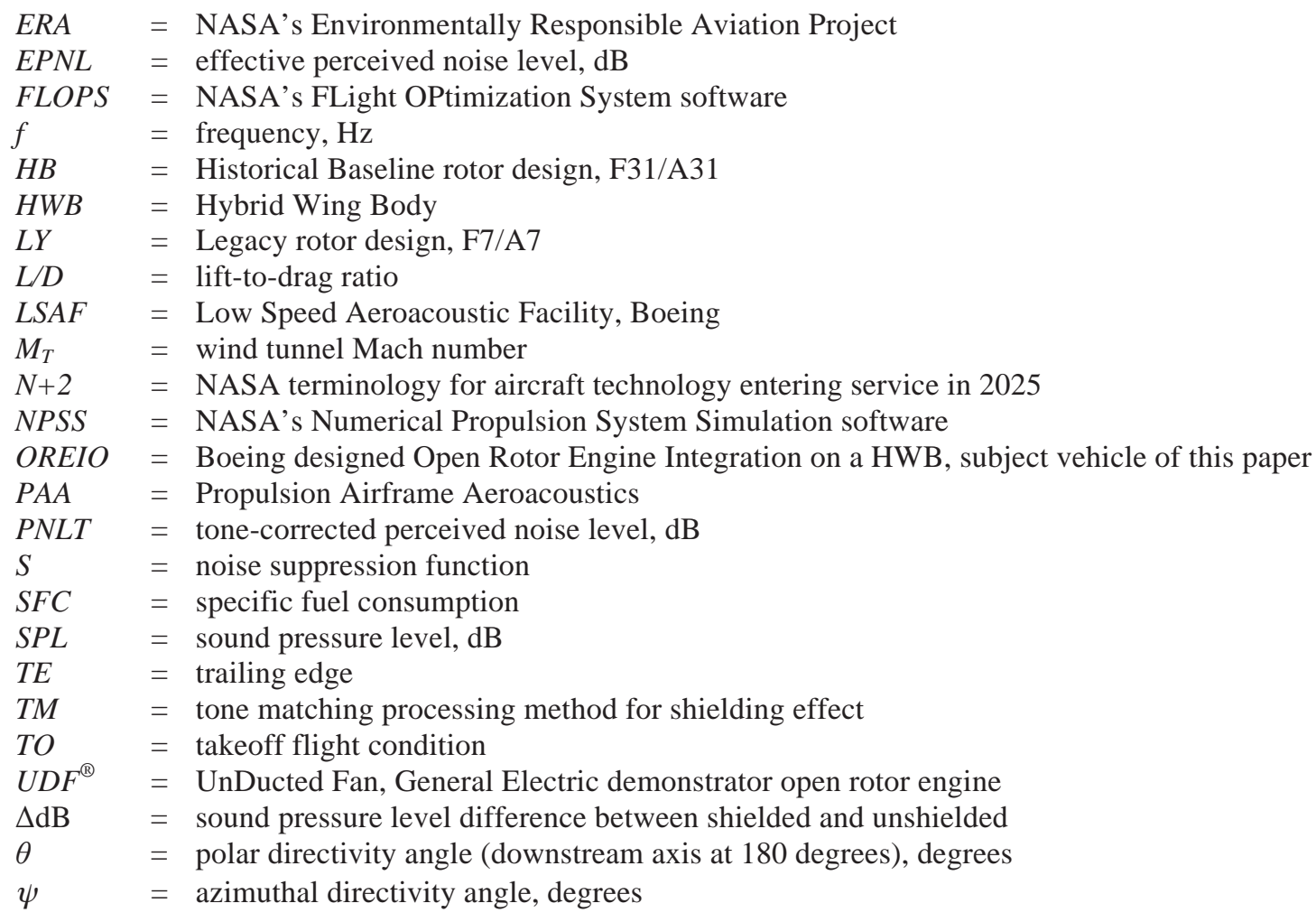

\section{Introduction}

Aybrid Wing Body (HWB) aircraft with an open rotor propulsion system represents a concept that could combine the low fuel burn potential of the open rotor with the low community noise potential of the HWB where the propulsion system is mounted on the upper surface of the HWB, ${ }^{1}$ Fig. 1.

The open rotor propulsion system is an architecture that accomplishes a very high effective bypass ratio and was the subject of considerable development work in the 1980s. This work advanced understanding of open rotor noise enabling the design of blades that could exceed the requirements for the Stage 3 noise rule of the time. ${ }^{2-5}$ There was also research on the installation effects relevant to a tail mounted tube-and-wing aircraft, ${ }^{6,7}$ the leading aircraft configuration studied at that time for the application of an open rotor propulsion system. The open rotor programs of the 1980s culminated in two development engines, one from GE Aircraft Engines known as the UnDucted Fan $\left(\mathrm{UDF}^{\circledR}\right)$ and one from Pratt and Whitney/Allison known as the 578-DX, ${ }^{8}$ as well as associated flight testing programs. For example, the GE $\mathrm{UDF}^{\circledR}$ engine was flight tested on a Boeing $727^{9}$ and then on a MD-80. ${ }^{10}$ Even with the considerable accomplishments of these projects an aircraft product was not launched likely due to a number of reasons including the sharp reduction in the price of fuel during the late 1980 s to early 1990 s and the open rotor's still relatively high noise levels. Bowles ${ }^{11}$ provides an excellent historical overview.

Influenced greatly by the volatility in the cost of fuel, open rotor research first diminished in the 1990s and then was reinvigorated during the last several years as the price of oil has continued to remain close to $\$ 100$ per barrel for much of the

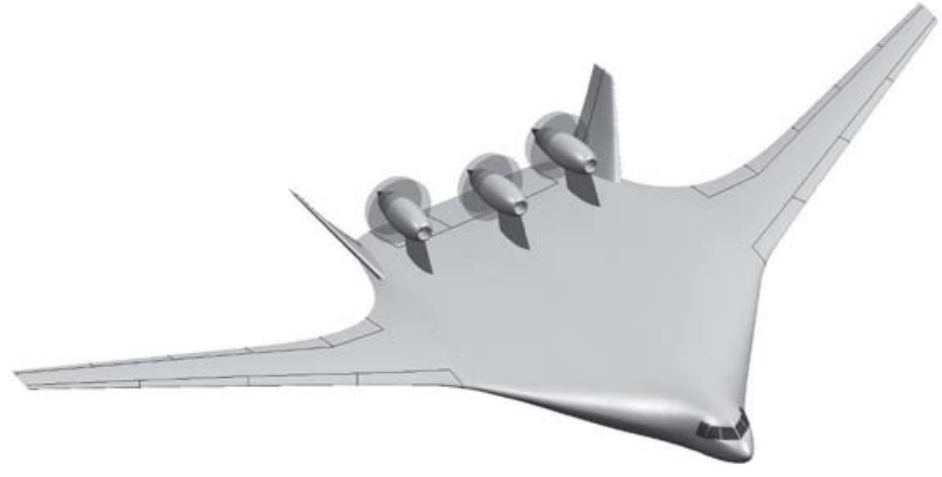

Figure 1. OREIO Hybrid Wing Body aircraft concept with open rotor propulsion system (Image credit Boeing ${ }^{12}$ ). 
time since 2007. With the Stage 4 noise regulation having been instituted in the last decade, modern open rotor research has again emphasized achieving lower open rotor source noise levels to meet the Stage 4 requirement with a margin sufficient for a commercial aircraft product.

NASA's Environmentally Responsible Aviation (ERA) Project ${ }^{13}$ has focused since 2009 on developing and demonstrating technologies for integrated aircraft systems that could meet simultaneously aggressive goals for fuel burn, noise, and emissions. The fuel burn goal is a reduction by $50 \%$ relative to a best in fleet aircraft in 2005, the noise goal is $42 \mathrm{~dB}$ cumulative relative to the Stage 4 requirement, and the emissions goal is for a reduction of $75 \%$ in NOx below the CAEP 6 (Committee on Aviation Environmental Protection) standard. The target date is 2020 for key technologies to be at a technology readiness level (TRL) of four to six (system or sub-system prototype demonstrated in a relevant environment). This corresponds to a projected aircraft entry into service of 2025 . These goals and timeframe are defined by NASA as $\mathrm{N}+2$.

Of the three goals, the noise goal is the most challenging to meet with an open rotor propulsion system despite the considerable progress having been achieved in blade design for low noise with high efficiency. The installation of an open rotor system on the upper surface of a HWB and the propulsion airframe aeroacoustic integration effects from this configuration raise the question as to the potential level of community noise reduction that could be achieved with this unconventional concept.

However, the installation of an open rotor propulsion system on a HWB has particular challenges not just for the aeroacoustic effects but for performance and the overall aircraft level trades. The rotors are unducted and exposed to flow conditions from the airframe flow field and angle of attack. Open rotors are larger in diameter and, therefore, require longer and heavier pylons compared to an equivalent conventional turbofan. The flow field velocities that the rotors are immersed in may be higher than the free stream flow and may not be uniform, both of these characteristics could increase noise and decrease performance. Absent a nacelle, open rotors may also cause changes in the flow conditions imposed on the aircraft surfaces in the vicinity of the propulsion system. At high power conditions such as takeoff and climb out, the stream tube of air that goes through the rotors contracts rapidly causing the boundary layer on the body upper surface to go through an adverse pressure gradient which could lead to flow separation. Perhaps most significantly, in order to take advantage of the low noise potential of the HWB, the engines must be positioned upstream of the trailing edge exacerbating many of these same design challenges. Overall, the open rotor HWB configuration must be designed with low noise objectives but also to mitigate these particular challenges in order to reach the best and balanced, fuel burn and noise reduction goals.

NASA's ERA project funded Boeing Research and Technology in Huntington Beach, CA to develop a conceptual level design of a HWB open rotor concept intended for entry into service of 2025 and meeting the ERA project goals. This effort resulted in the conceptual aircraft design referred to as OREIO, ${ }^{12}$ which stands for Open Rotor Engine Integration on a HWB. This aircraft concept design, source noise for a projected advanced rotor design,${ }^{14}$ together with experimental data from a recent Propulsion Airframe Aeroacoustic (PAA) installation experiment at Boeing's Low Speed Aeroacoustic Facility (LSAF) ${ }^{15}$ were the key source material specific for the rigorous system noise assessment of an HWB with open rotor propulsion in this paper.

This paper will present the details of the noise assessment and describe the prediction process. It will include additional analysis of the effects from key parameters and some potential noise reduction approaches that could constitute a technical roadmap toward a low noise HWB open rotor concept to meet the $42 \mathrm{~dB}$ noise goal of ERA assuming the technical maturation is successful. However, the performance impact or aircraft system level trade implications of such a low noise technology roadmap are not assessed in this paper and are left to future work.

\section{Framework}

\section{A. Previous Studies}

GE, the FAA, and NASA have recently collaborated on a series of modern blade designs and tests in the NASA Glenn Research Center's 9x15 Low Speed Wind Tunnel and this work is summarized by Van Zante. ${ }^{16}$ After the test campaign, GE and NASA collaborated on a system study of a single aisle aircraft concept with tail mounted open rotor engines. The open rotor propulsion system was assessed with performance and acoustics based on the wind tunnel test campaign results. NASA defined a 1998 technology airframe and then defined an advanced technology version of the airframe that would represent an aircraft for application in the 2020 timeframe, or N+1 in NASA's goal definition. NASA worked with GE to define the open rotor core engine cycle appropriate for application in 2020. The initial assessment showed a cumulative margin to Stage 4 of 13 EPNLdB with a fuel burn reduction of $33 \%$ relative to the 1998 baseline aircraft. ${ }^{17}$ An updated NASA assessment using the more advanced blade design 
test results (from the same test campaign ${ }^{16}$ ) showed the noise margin to be 16.8 EPNLdB. ${ }^{18}$ And a related study by GE showed a similar margin of 15-17 EPNLdB below Stage $4 .{ }^{19}$

As part of a NASA contract from ERA referred to as the Advanced Vehicle Concept (AVC) task, three industry led teams developed aircraft concepts targeted to the NASA N+2 goals with aircraft entry into service of 2025. The three industry teams were led by Boeing Research and Technology, Lockheed Martin Aeronautics, and Northrop Grumman.

Boeing included a HWB aircraft with three open rotor engines ${ }^{20,21}$ in their set of aircraft concepts studied. Because this paper focuses only on a HWB with open rotor propulsion, the Boeing AVC HWB with open rotor engines will be referred to in this paper as the AVC vehicle. The OREIO HWB of this paper and the AVC of the Boeing AVC contract work are in many ways very similar, however, there are also several significant differences between these concepts. Both aircraft were designed by Boeing Research and Technology based on their best practice HWB methods. The AVC vehicle is a passenger aircraft while the OREIO is a freighter aircraft. Both have three open rotor engines. The AVC vehicle used Rolls-Royce engines. The OREIO vehicle used an engine concept that NASA Glenn Research Center developed, in part, from information and experience going back to the 1980s work with GE on the $\mathrm{UDF}^{\circledR}$ demonstrator engine.

The noise assessment of the AVC vehicle was reported in a companion paper by $\mathrm{Guo}^{22}$ and comparisons to the noise assessment results in this paper will be noted. For both studies, the experimental acoustic data from Czech and Thomas ${ }^{15}$ was used to assess the PAA installation effects, in particular due to shielding. Companion papers by Bahr et al. $^{23}$ and Guo et al. ${ }^{24}$ show how this experimental data was processed for use in these aircraft system level assessments.

\section{B. Current Study Framework}

The overall goals and the framework of the study reported here follow that of a previous NASA pathfinding study $^{25,26}$ for the $\mathrm{N}+2$ goal. A rigorous noise assessment method was used deploying the best available information including experimental acoustic data directly in the noise assessment process because prediction methods for PAA effects are as yet inadequate. In regards to this fundamental approach, the study of Guo ${ }^{22}$ and the current study are very similar. Guo ${ }^{22}$ focuses on an assessment of the baseline aircraft with only the most realistic design features and technologies for the $\mathrm{N}+2$ timeframe. In addition to the baseline aircraft, this current study examines the additional impact of key design parameters and some technologies that may only be at an early development stage. The purpose of this additional assessment is to propose a possible roadmap for pursuing an even lower noise aircraft concept compared to the baseline with the understanding that future work is needed to examine how to achieve these design objectives in the context of a balanced aircraft design process.

\section{OREIO Aircraft and Open Rotor Propulsion System}

\section{A. Open Rotor Engine}

On contract to NASA, Boeing developed the aircraft model for the OREIO with an open rotor propulsion system to meet the requirements for a subsonic freighter configured transport ${ }^{12}$ with a payload of 100,000 lbs at a range of $6500 \mathrm{~nm}$ and a cruise Mach number of 0.8 . The resulting vehicle has a takeoff weight of 471,993 lbs. Boeing also factored in assumptions for the application of hybrid laminar flow and riblet technologies as well as an advanced composite structure. A schematic of the resulting vehicle concept is shown in Fig. 1. For this study, this vehicle was considered the baseline configuration for the freighter aircraft.

The NASA Glenn Research Center Engine Systems Analysis group developed and supplied the engine model to Boeing for integration with the airframe. Based on the requirements from

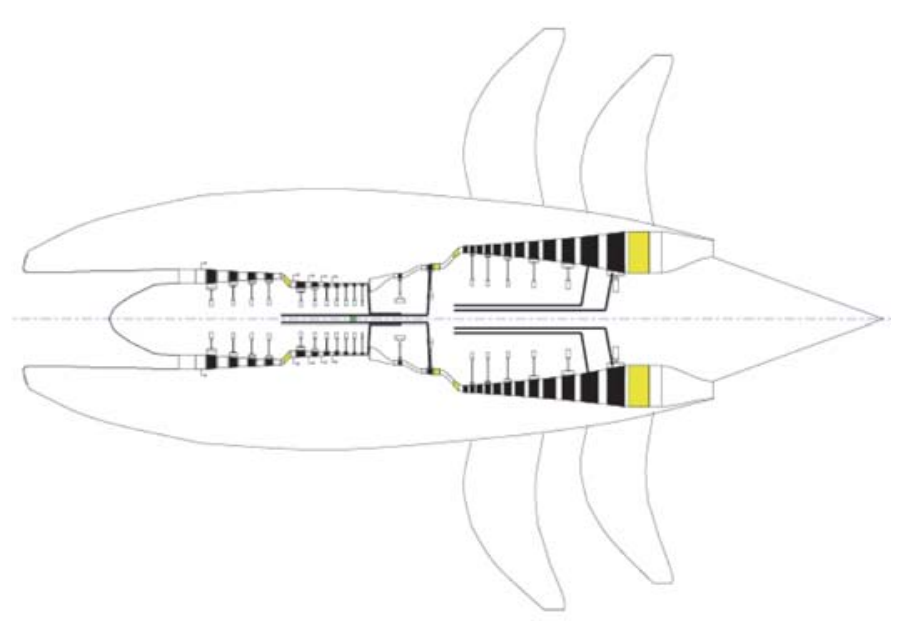

Figure 2. Schematic of the open rotor engine system modeled by NASA Glenn.

4 
Boeing, the engine was sized to produce a sea level static thrust of $37,525 \mathrm{lbs}$ per engine. Due to the limited amount of available information, the engine model incorporated modern core technology but with a 1980's era blade configuration consisting of the legacy F7/A7 blade design with eight forward blades and eight aft blades used on the GE UDF ${ }^{\circledR}$ demonstrator engine that was flight tested in the 1980 s. $^{9,10}$ This linkage also allowed the performance map information available to NASA to be used in assessing the performance of the resulting engine model as well as to provide the engine state parameters for assessing the noise. Clipping of the aft rotor (a smaller rotor diameter than that of the forward rotor) was incorporated with the objective of introducing a well known noise reduction feature suitable for the F7/A7 technology. The schematic of this baseline open rotor is shown in Fig. 2. The rotor diameter was set at $14 \mathrm{ft}$ for the OREIO application.

\section{B. Propulsion Airframe Integration}

To a preliminary level, the aerodynamic integration of the HWB and the open rotor engines was performed by Boeing. The external cowl and inlet geometry were defined by Boeing based on the GE UDF ${ }^{\circledR}$ experience and given the constraint of keeping the internal cross-sectional area approximately equal to the $\mathrm{UDF}^{\circledR}$ example. The open rotors were positioned between vertical stabilizer surfaces and upstream of the trailing edge to provide a substantial shielding surface for aft radiated noise as well as to incorporate the control elevons. Based on the wind tunnel test results ${ }^{15}$ the criteria for the shielding area was to locate the mid-point between the forward and aft rotor, a minimum of one rotor (forward rotor) diameter upstream of the trailing edge. Boeing assessed the interference drag computationally for different configurations of the three engine nacelles with the vertical stabilizers and determined that staggering the engine nacelles resulted in a significant improvement. It was decided to offset the center engine by moving it upstream. In this way, the center engine had more aft shielding surface area while the two outboard engines had the additional shielding due to the vertical stabilizers. A three-view of the OREIO is shown in Fig. 3.

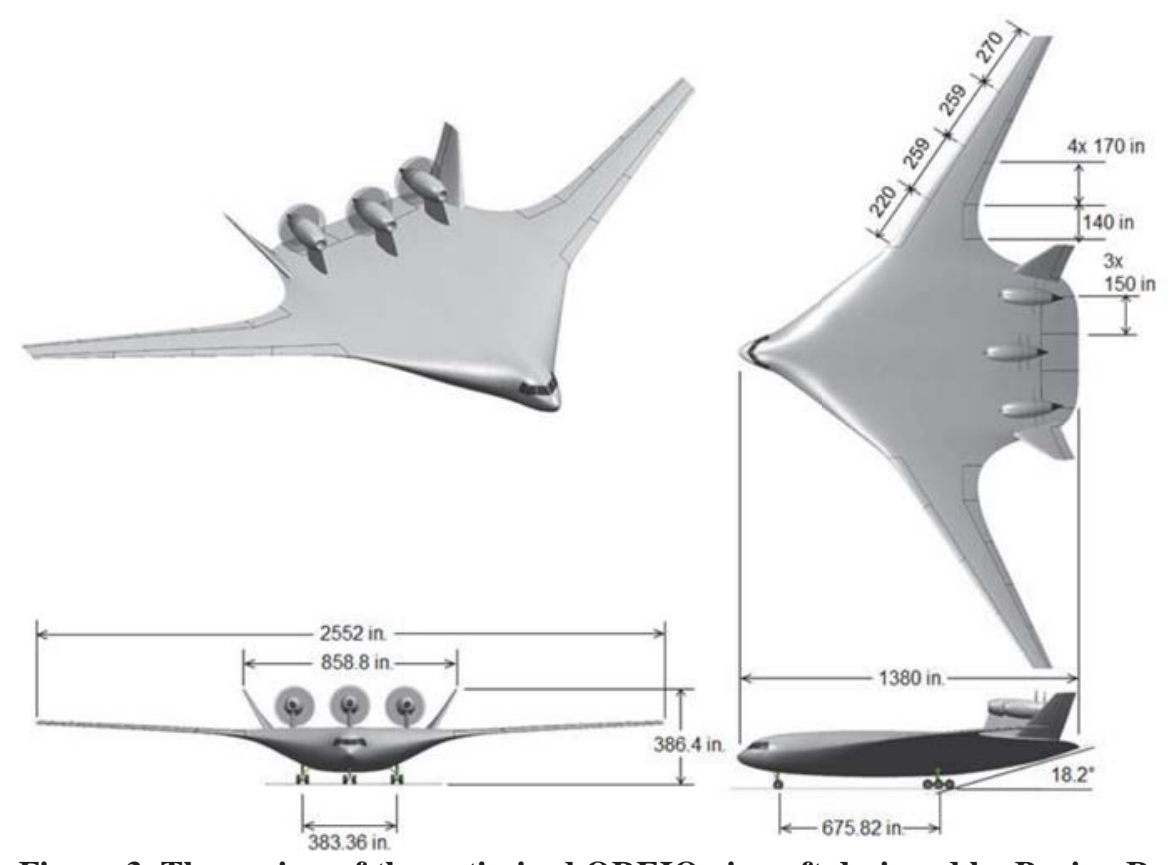

Figure 3. Three-view of the optimized OREIO aircraft designed by Boeing Research and Technology ${ }^{12}$.

\section{OREIO Aircraft Performance}

Performance requirements for the OREIO design were based on the NASA ERA requirements, see Table 1. For the OREIO study, NASA specified a HWB freighter configuration with a 100,000 lb payload capacity, including the cargo container tare weight. Wingspan was constrained to the $213.25 \mathrm{ft}(65 \mathrm{~m})$ limit for ICAO Code E airports, a reasonable limit for this capacity HWB that, unconstrained, optimizes near this span. Wing folding was not 
considered in the interest of simplicity, although it may be entertained in future studies. The objective function for design optimization was fuel consumption. The final OREIO geometry was then refined based on experience and is shown in Fig. 3. ${ }^{12}$

Table 1. Boeing HWB Performance Requirements

\begin{tabular}{|c|c|c|}
\hline Requirement & $\begin{array}{l}\text { OREIO }^{12} \\
\text { Freighter }\end{array}$ & $\begin{array}{c}\text { AVC }^{20,21} \\
\text { Passenger }\end{array}$ \\
\hline Payload & $100,000 \mathrm{lbs}$ & 224 passengers \\
\hline Design range & $6,500 \mathrm{~nm}$ & $8,000 \mathrm{~nm}$ \\
\hline $\begin{array}{l}\text { Critical field length (SL Std. } \\
\text { Day @ MTOGW) }\end{array}$ & $10,500 \mathrm{ft}$ & \\
\hline Standard for field length & FAR & \\
\hline Approach speed (knots) & 155 & 146 \\
\hline $\begin{array}{l}\text { Landing field length (SL Std } \\
\text { Day @ MLW) }\end{array}$ & $5,200 \mathrm{ft}$ (dry) & \\
\hline Initial cruise altitude & $35,000 \mathrm{ft}$ & $35,000 \mathrm{ft}$ \\
\hline Maximum cruise Mach number & 0.8 & 0.85 \\
\hline Maximum sink rate@ landing & $8 \mathrm{ft} / \mathrm{sec}$ & \\
\hline Wingspan constraint & $213.25 \mathrm{ft}(65 \mathrm{~m})$ & $229.3 \mathrm{ft}$ \\
\hline Measure of merit & $\begin{array}{l}\text { Gross payload ton- } \\
\mathrm{nm} / \mathrm{lb} \text { fuel burned }\end{array}$ & $\begin{array}{c}\text { Fuel burn, noise, } \\
\text { emissions, direct } \\
\text { operating cost }\end{array}$ \\
\hline
\end{tabular}

The vertical tail was sized relative to rules of thumb established by NASA from acoustic testing in the LSAF tunnel. Based on these results, NASA suggested sizing rules for the root chord and tip chord relative to the forward rotor diameter. The root chord should be about $1.25 \mathrm{D}$ and the tip chord should be about $0.60 \mathrm{D}$. The root chord and tip chord for the revised vertical tail are 1.13D and $0.48 \mathrm{D}$. The revised vertical tail was close to the recommended size for acoustics but slightly undersized. Tail sizing was also checked relative to stability and control requirements. The OREIO configuration and the X-48C are very similar, and the X-48C was evaluated in great detail. Therefore, the X-48C tail volume was considered a very good preliminary sizing requirement for the OREIO. The OREIO configuration has approximately the same tail volume as the X48-C, which implies that the OREIO tails were properly sized for stability and control. Therefore, the vertical tail size was not increased.

The designed performance of the OREIO is summarized in Table 2 providing all the aircraft level parameters needed for the system noise assessment process.

Table 2. OREIO Performance Summary

\begin{tabular}{lc}
\hline \hline & $\begin{array}{c}\text { OREIO }^{\mathbf{1 2}} \\
\text { (Freighter) }\end{array}$ \\
\hline Weight-takeoff (lbs) & 470,138 \\
Weight-landing (lbs) & 357,773 \\
Max fuel (lbs) & 127,621 \\
Initial cruise SFC (lbm/hr/lbf) & 0.4395 \\
L/D (start of cruise) & 22.849 \\
Thrust per engine (static sea level) & 37,525 \\
Throttle: approach (full throttle = 1.0) & 0.11 \\
Throttle: sideline & 1.00 \\
Throttle: cutback & 0.69 \\
Balanced field length @ SL, 59F (ft) & 8,118 \\
\hline \hline
\end{tabular}




\section{System Noise Assessment Process}

\section{A. Process Overview}

The system noise assessment process was structured so that the best system noise prediction methods and the best experimental data available were used in the assessment of aircraft system level noise. For this study, the new NASA system noise prediction framework, ANOPP $2{ }^{27}$ was used which includes the existing ANOPP ${ }^{28}$ code that has been in existence and continuously updated since the 1970s as well as new capabilities that allow for acoustic data processing and propagation effects. The process basically consists of defining the aircraft configuration along a flight path for which the aircraft source noise is computed and propagated to far-field observers. Figure 4 shows the data and prediction components of this process which include results from aircraft conceptual analysis, experimental measurements, and prediction modeling. The OREIO vehicle concept study ${ }^{12}$ provided the aircraft flight definition. The full scale OREIO open rotor noise sources were obtained through processing model scale measurements within ANOPP2. The component source noise for the engine core and airframe components identified in Fig. 4 were predicted using ANOPP. The open rotor installation effects and noise reduction technologies were accounted for through the use of direct measurements and suppression maps applied within the ANOPP2 framework. With the aircraft source noise determined, the final step in the process was to propagate the noise to ground observers omitting the tone correction penalties for fictitious pseudotones. ${ }^{17}$ Next, each of these are described more fully.

The OREIO vehicle concept study ${ }^{12}$ provided not only the aircraft design definitions but the flight characteristics including the flight definition for certification approach and takeoff operations. The OREIO engine system model was developed by NASA Glenn Research Center Engine Systems Analysis using NASA's Numerical Propulsion Simulation System ${ }^{29}$ (NPSS). This model provided the operating state of both the open rotor and components of the engine including the core and jet. For the propulsion noise assessment, only the open rotor and core components were considered since they dominated over the other engine components (the jet noise was insignificant compared to the core and even more so compared to the open rotor sources due to its low velocity). The core noise was computed using ANOPP GECOR model as shown in Fig. 4, which is a semi-emipirical model developed and validated using traditional turbofan engine noise data. Its application for predicting open rotor engine noise is within its range of valid input parameters, however a comparison between prediction and measured noise has not been performed due to availability of measured data.

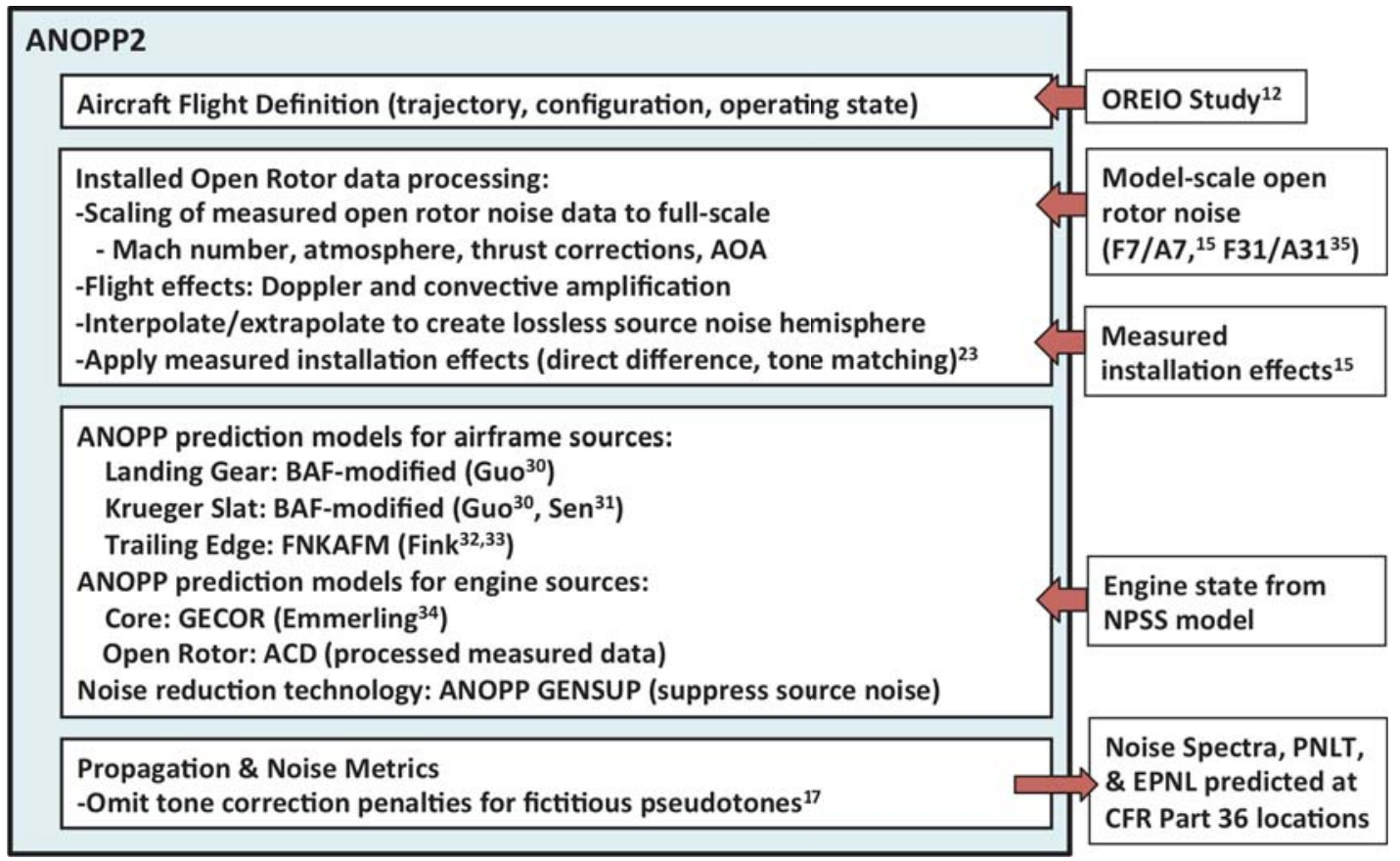

Figure 4. System noise prediction process using noise models and measured data. 
The open rotor noise was obtained from model scale measurements for both isolated and installed configurations. These noise measurements were processed within ANOPP2 to create full-scale open rotor noise definition on a $1 \mathrm{ft}$ lossless source noise hemisphere of observers accounting for scale, Mach number, thrust, Doppler, convective amplification and atmospheric condition differences between the measurements and requirements of the OREIO flight definition. The installed configurations including those associated with open rotor/airframe integration as well as noise technologies applied to the rotor (aft rotor blade clipping, pylon blowing, and angle of attack) are identified in Table 3 and fully described later in the paper. The installed effects in the form of suppression maps were developed for each installation and noise technology effect so that they could be applied to noise from arbitrary open rotor designs for the prediction of installed noise ${ }^{25}$ as well as used directly in ANOPP via the GENSUP module to account for noise technologies on source noise predictions. Linear interpolation and last value extrapolation provided full definition of the noise and suppression levels over the complete source noise hemisphere prior to ANOPP insertion via the ACD module as indicated in Fig. 4. The suppression maps are a function of frequency at every polar, $\theta$, and azimuthal, $\psi$, angle on the noise source hemisphere. The suppression $\mathrm{S}$, is the ratio of the shielded to unshielded mean square pressures and is given by

$$
S(f, \theta, \psi)=\frac{P_{r m s}^{2}(f, \theta, \psi)_{\text {shielded }}}{P_{r m s}^{2}(f, \theta, \psi)_{\text {unshielded }}}=10^{\left(\frac{\Delta d B}{10}\right)}
$$

where $\Delta \mathrm{dB}=\mathrm{SPL}_{\text {shielded }}-\mathrm{SPL}_{\text {unshielded }}$. Thus $\mathrm{S}<1$ indicates suppression and $\mathrm{S}>1$ indicates amplification.

The airframe noise source components including landing gear, leading edge Krueger slat, and trailing edge were predicted using ANOPP methods shown in Fig. 4. The BAF module of ANOPP includes methods for landing gear and conventional slat noise prediction. The landing gear method assumes a tube-and-wing fuselage and internally computes the flow into the landing gear based on that configuration. For a HWB application such as the OREIO the flow velocity into the landing gear is about $15 \%$ higher than for a tube-and-wing aircraft. For this study the method was modified to account for this difference in flow velocity in computing both the nose and main gear noise. Due to the lack of data and availability of prediction models for Krueger slats, the ANOPP (BAF) slat prediction method was modified to estimate this noise source. The predicted conventional slat noise source levels were reduced by 1.5 $\mathrm{dB}$ spectrally, uniformly for all frequencies, to represent the Krueger slat source noise levels. This estimate was based on the reasoning of Guo. ${ }^{20,22}$ The trailing edge of the OREIO airframe including the verticals were computed using the ANOPP method based on Fink. ${ }^{32,33}$ Both the Krueger slat and trailing edge predictions have the least confidence due to the fidelity of the methods used and the details of the geometry required for these predictions.

To compute the noise metrics at far-field observers, all of the ORIEO source noise components and PAA installation effects are summed together at each location along the flight path and propagated to the ground accounting for atmospheric propagation and ground effects The noise metrics include the PNLT as well as EPNL for the aircraft total and component noise and are used in the assessment of the OREIO relative to the FAA's Stage 4 requirements and the NASA $\mathrm{N}+2$ noise goal.

The NASA noise goals are stated in reference to the cumulative CFR Part 36 certification noise limits. The certification flight procedures as defined by the CFR 36 Stage 3 regulations ${ }^{36}$ were used by Boeing to define the flight trajectories for approach and takeoff. The geometric position of the three noise measurement locations according to the CFR 36 for jet aircraft (Section B36.3(a)(1) of Part 36) are shown in Fig. 5. For large propellerdriven transports, the Lateral (Sideline) reference location is defined to be directly under the flight path where the aircraft reached an altitude of $2133 \mathrm{ft}(650 \mathrm{~m})$ rather than to the side at $1476 \mathrm{ft}(450 \mathrm{~m})$ as shown in Fig. 5. In this study, to allow direct comparison with noise from similar sized jet-driven aircraft and with results from other NASA studies relating to the N+2 noise goal, the OREIO Sideline location is set at $1476 \mathrm{ft}$ laterally and when the aircraft is at $1000 \mathrm{ft}$ altitude. 


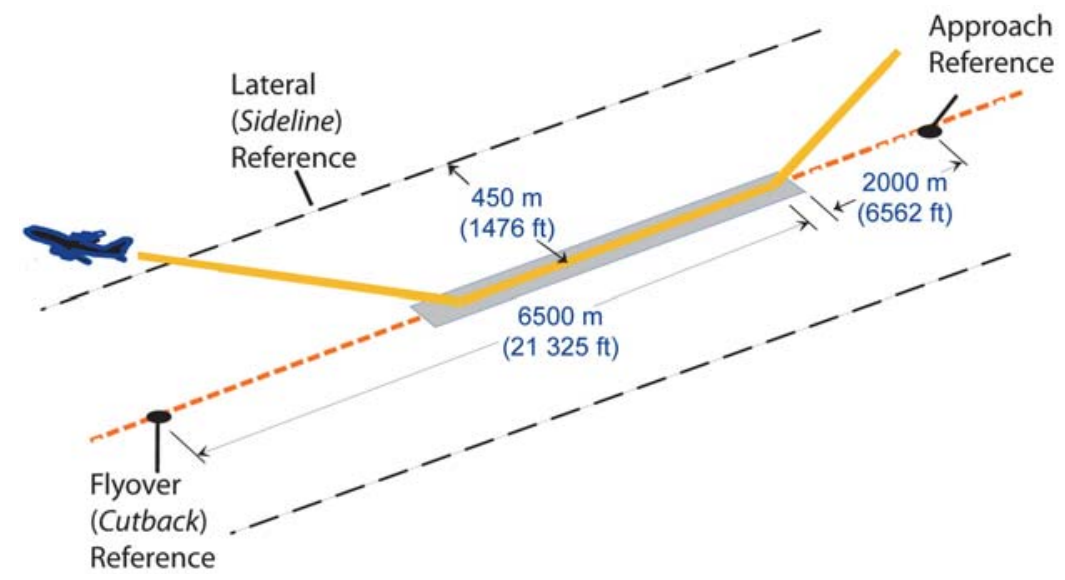

Figure 5. CFR 36 noise certification measurement locations for aircraft approach and takeoff trajectories.

\section{B. Flight Path}

The flight path and aircraft condition data is shown in Figs. 6-9 for the both the OREIO freighter and, for comparison, the AVC passenger vehicle. The AVC information was obtained from Guo, ${ }^{22}$ except for the net thrust (Fig. 9) which was not available. The flight path segment associated with the ground operation was not modeled and hence was omitted from the figures. The end of the approach segment is at $0 \mathrm{ft}$ (distance) on the $\mathrm{x}$-axis in Figs. 6-9 and defined when the aircraft reached the end of the runway at an altitude of $50 \mathrm{ft}$. For the takeoff segment, $0 \mathrm{ft}$ (distance) on the $\mathrm{x}$-axis in Figs. 6-9 is the location of brake release. The difference in flight path definition for the OREIO aircraft and the AVC aircraft is clearly seen.

Due to the heavy weight and reduced lift to drag ratio of the OREIO compared to the AVC, the OREIO vehicle requires a higher approach velocity $(\sim 5 \%)$ and a longer ground roll. The AVC is about $11 \%$ lighter than the OREIO at takeoff, which in part contributes to its steeper climb angle. Due to the shallower climb angle of the OREIO, its altitude is only slightly greater than $1000 \mathrm{ft}$ at the start of the cutback segment. All of these differences will tend to increase the noise levels compared to a flight path flown by the AVC. Following the same computational process used in the AVC study, the noise levels at the three certification reference points (approach, sideline, cutback) were determined with separate computations. For the sideline noise prediction the full-power segment in Fig. 6 was extended in the downrange distance and for the cutback noise prediction the cutback segment in Fig. 6 was extended in both the uprange and downrange distance. This was done to avoid noise contamination between the higher power takeoff and cutback conditions and to be consistent with other published results. ${ }^{17,22}$

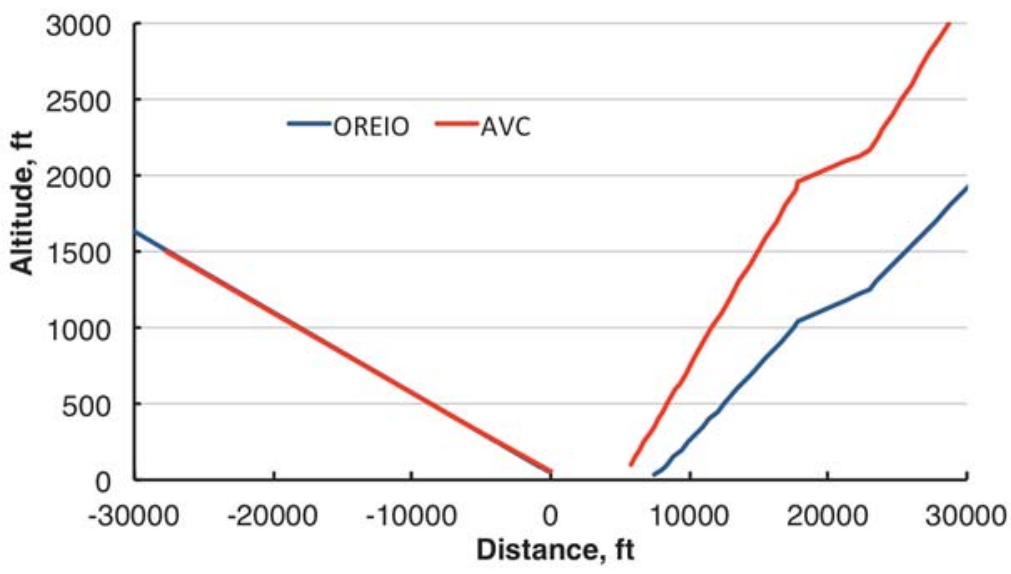

Figure 6. Approach (negative distance toward zero) and takeoff (positive distance away from zero) altitude profiles for the OREIO and AVC aircraft models. 


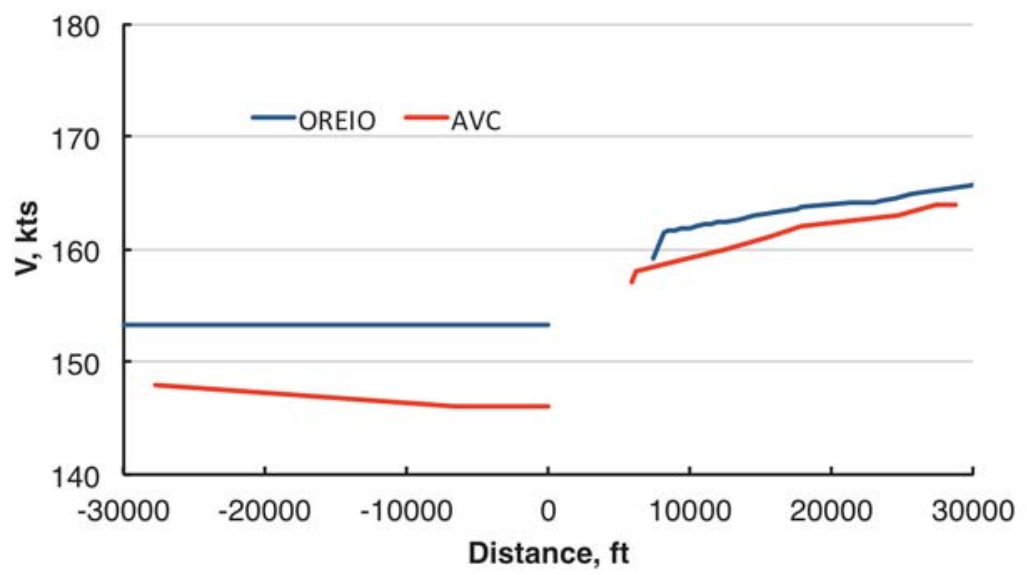

Figure 7. Approach (negative distance toward zero) and takeoff (positive distance away from zero) velocity profiles for the OREIO and AVC aircraft models.

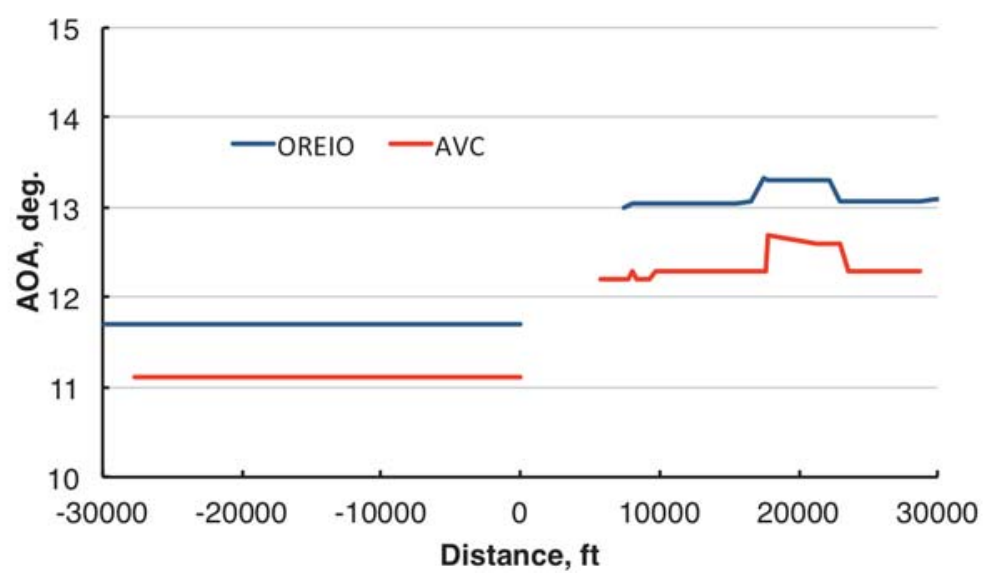

Figure 8. Approach (negative distance toward zero) and takeoff (positive distance away from zero) angle-ofattack profiles for the OREIO and AVC aircraft models.

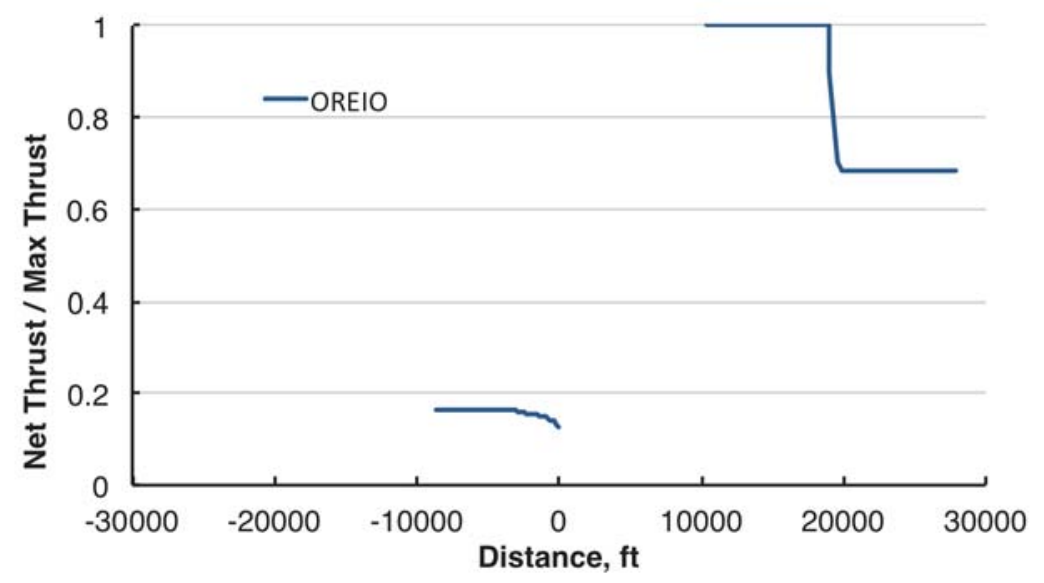

Figure 9. Approach (negative distance toward zero) and takeoff (positive distance away from zero) thrust profile for the OREIO aircraft model. 


\section{Airframe Noise Sources}

The airframe sources considered in this study include the nose and main landing gear, trailing edge, and the leading edge Krueger slat. The baseline airframe component noise was assessed followed by additional configurations that include projected, aggressive levels of noise reduction from technologies that could be available in the $\mathrm{N}+2$ timeframe. The projected noise reduction technology was applied to the landing gear but not to the Krueger slat or the trailing edge.

Noise from landing gear is found to be an important airframe noise component for many current aircraft. Studies of future low noise aircraft concepts increasingly show landing gear as a dominant airframe noise component on approach, a finding due to reductions predicted for the other aircraft sources. ${ }^{22,37}$ The main and nose gear noise are highly dependent upon the design details of each gear assembly and their installation on the aircraft. There have been a number of studies that have characterized the gear noise, both in level and directivity, ${ }^{38}$ as well as proposed gear noise reduction, which include rearrangement of elements of the gear and flow streamlining through various types of fairings. ${ }^{39-42}$ Based on these and other studies, combined with experience from ongoing model scale tests and numerical simulations of low-noise gear designs, a range of noise reduction projections for both nose and main gear ${ }^{43}$ were determined and used in recent NASA studies. ${ }^{25,37}$ In this study, for the purpose of estimating what the largest potential noise reductions could be, the nose gear and the main gear are reduced for their components by 7 $\mathrm{dB}$ and 3-5 dB, respectively, as a function of frequency. This reduction was applied in configurations labeled as including landing gear noise reduction.

\section{Open Rotor Source Noise Modeling}

Open rotor acoustic data from scaled model tests was used as the open rotor source definition within the ANOPP2 ${ }^{27}$ system noise prediction. There were three open rotor blade designs used in this study: the F7/A7 Legacy (LY) design, the Historical Baseline (HB) F31/A31 design, and the Advanced Quiet (AQ) design. The F7/A7 Legacy (LY) design was used on the GE UDF ${ }^{\circledR}$ demonstrator engine in the 1980s. This blade design was also tested in a rotor alone, isolated, configuration by Czech and Thomas ${ }^{15}$ in the NASA/Boeing Open Rotor PAA Installation Effects test. In addition, acoustic data on installation effects required for the current study was also acquired. The open rotor design referred to as the Historical Baseline (HB) F31/A31 design was the best aerodynamic performance design with acceptable noise from the early 1990s timeframe. Van Zante el al ${ }^{35}$ reports results of the F31/A31 aeroacoustic wind tunnel testing performed in recent years to reacquire data for this Historical Baseline design with the benefit of modern techniques and instrumentation. The Advanced Quiet (AQ) rotor design is a projection proposed by Van Zante et al., ${ }^{14}$ developed from the experience of the extensive NASA/GE/FAA Open Rotor campaign ${ }^{16}$ of recent years to project the best low noise open rotor source noise levels that could be available in the $2025 \mathrm{~N}+2$ timeframe. The value of the projection was for an additional $6 \mathrm{~dB}$ lower than the F31/A31 and was applied over the whole spectra for both tones and broadband.

The F7/A7 and the F31/A31 noise data were obtained at different model scales and both were scaled to the full scale size of the OREIO. Relative to the full-scale ORIEO, the F7/A7 model is 7.14\% and the F31/A31 is $15.27 \%$. Both the F7/A7 and F31/A31 acoustic databases contain data for noise certification conditions representing takeoff, cutback, and approach for aircraft applications envisioned other than the OREIO design and hence they do not match the noise certification conditions required for the OREIO. As an example, the F7/A7 sound power level was determined by integrating over the source noise hemisphere defined from the measurements for six different thrust levels. Figure 10 shows the power levels and thrust scaled to that of the full-scale OREIO vehicle. The thrust range of F7/A7 data did not span the full range required by the ORIEO vehicle and, therefore, the acoustic power levels for the OREIO sideline condition was obtained by extrapolation as shown by the curve fit line in Fig. 10. 


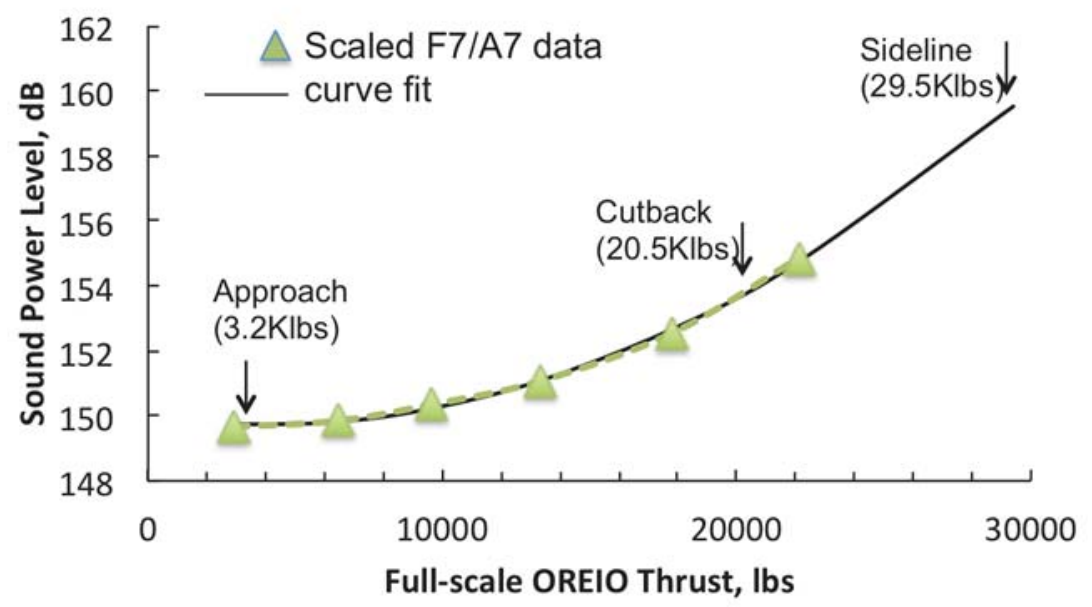

Figure 10. Acoustic power level versus full-scale OREIO thrust for the F7/A7 model open rotor. OREIO thrust levels per rotor for approach, cutback, and sideline are indicated.

\section{Noise Assessment Configurations}

Aircraft system noise assessment results are presented in the following section. The OREIO aircraft noise was predicted for a baseline configuration and then with various configuration changes and technology effects added or "turned on" in order to quantify their acoustic effects. In this way, the impact at the aircraft system level can be identified. Table 3 summarizes the configurations that were assessed building up in progression from the isolated open rotor engine to the complete low noise aircraft. The following section is a description of these configurations before results are presented.

\section{A. Airframe and Engine Configurations}

The first four configurations in Table 3 are isolated open rotor engine configurations and they are meant to build up effects in preparation for installation on the OREIO vehicle in subsequent configurations. The first four isolated rotor configurations and all aircraft configurations in Table 3 include the summation for three open rotor engines. Configuration IRA is the isolated rotor baseline with zero degree angle of attack, no pylon blowing, and no clipping effects. Pylon blowing is expected to be a noise reduction technology given the pusher open rotor configuration on the OREIO and, therefore, configuration IRB adds the pylon blowing effects that were documented in the experimental data to IRA. Both IRA and IRB are configurations whose noise levels and directivity were obtained directly from the experimental data. ${ }^{15}$

Clipping of the aft rotor is an expected design feature on the open rotor of the OREIO. Therefore, the clipping effect was implemented from data reported by Woodward et al. ${ }^{4,5}$ This effect was added to the IRB noise level and directivity by adjusting the tone levels affected by clipping and the result produces the IRC configuration.

Angle of attack (AOA) to the rotor plane is a primary parameter impacting isolated rotor noise and installed noise. When the rotor is installed on the OREIO vehicle, the rotor will see an angle that has the combined effects due to the AOA of the vehicle on it's flight path and due to the flow curvature over the airframe. Analysis of the flow field was conducted on the OREIO ${ }^{12}$ and AOA was a parameter tested in the experimental data. ${ }^{15}$ The OREIO has an AOA of between $11^{\circ}$ and $13^{\circ}$ for takeoff and approach conditions. However, the HWB airframe itself tends to lessen the AOA of the flow field that approaches the rotor and, therefore, the rotor face will experience a reduced angle compared to that of the overall ORIEO vehicle. Seven degrees of AOA to the rotor was chosen because experimental data was available and this angle was representative of what the computational studies showed considering a mean angle as well as some nonuniformity. Seven degrees was also seen as a conservative choice (higher noise) based on the expectation that as the vehicle design is refined the angle to the rotor may likely be reduced. Configuration IR0 uses experimental data for the effect of seven degrees of angle of attack to add this effect to the noise signature of IRC. In this way, a noise signature (IR0) for three open rotors together was obtained that includes the effects of pylon blowing, clipping of the aft rotor, and the effect of angle of attack. 
Configuration $\mathrm{OH} 0$ is an aircraft configuration construct where all the individual noise sources were included but without any shielding installation effects. This includes the engine, both rotor and core noise, and the airframe including Krueger flap leading edge, nose and main landing gear and trailing edge noise sources. IR0 is used as the rotor noise source while the core noise is predicted by ANOPP. The airframe sources are predicted by ANOPP with estimation included for the baseline Krueger flap leading edge as described in Section IV A. The integrated noise metrics for $\mathrm{OH} 0$ are calculated using the OREIO flight path and conditions, however, no shielding effect was included. $\mathrm{OH} 1$ and $\mathrm{OH} 2$ were omitted from the table as they do not add value to this discussion.

Configuration $\mathrm{OH} 3 \mathrm{~A}$ includes the shielding effect for the rotor installed at a location 1.0D upstream of the trailing edge of the OREIO. The shielding effect was obtained directly from the experimental data, ${ }^{15}$ the shielding from the experimental model airframe planform without elevons deflected or vertical surfaces. The experiment only included one open rotor simulator while the OREIO has three open rotors and the ORIEO staggers the three engines. The experiment did acquire most of the data in the off-center chordwise line on the port side of the airframe as shown in Fig. 11, however, some data was obtained with the rotor on the centerline of the planform airframe. For the purposes of this system noise assessment, the experimental data is superimposed to create a noise signature from three open rotors in the correct, staggered location relative to the trailing edge. The rotor noise signature for the rotor in the off-center position, port side, was symmetrically rotated to the orientation of the off-center position on the opposite side, starboard, of the airframe and then summed with the data from the centerline position. This summation assumed incoherence between the rotors and no additional interaction effects. The interaction effects between multiple engines and rotors is an area for refinement in future studies.

The acoustic scattering and shielding effect from the addition of the baseline vertical, $\mathrm{V} 1$, at a cant angle of $102^{\circ}$ (configuration $\mathrm{OH} 4$ ) was included using experimental data for this configuration. The effect of increasing the cant angle to $120^{\circ}$ was added to make $\mathrm{OH} 5$.

OH6 added the effect of elevon deflection from 0 to $5^{\circ}$ using data directly from the experiment. The model elevon was limited to three deflection angles of $+5^{\circ}$ (down), $0^{\circ}$, and $-5^{\circ}$ (up).

The airframe acoustic liner effect was added to make OH7. The liner is of a broadband type designed for maximum attenuation at the frequency range from BPF to $2 \mathrm{BPF} .{ }^{44}$ The liner installed on the experimental airframe is also shown in Fig. 11.

For configuration $\mathrm{OH} 8$ the effect of increasing elevon deflection was obtained by combining the experimental data with geometric analysis to project the effect of deflecting the elevon to the OREIO angle of $14^{\circ}$ for takeoff conditions. For the approach condition where the elevon angle is at zero on the OREIO, experimental data was used directly.

The effect of nose and main landing gear noise reduction was added on configuration $\mathrm{OH} 9$. The gear noise reduction was added to the ANOPP predictions as described in Section IV C.

For all configurations from $\mathrm{OH} 3 \mathrm{~A}$ to $\mathrm{OH} 9$ the rotors for all three engines were located in their staggered positions with the two outboard rotors at the baseline location of $1.0 \mathrm{D}$ upstream of the trailing edge. The rotor noise signature was based on the F7/A7 experimental data. OH10 moved the rotors in the same staggered position to 1.5D upstream of the trailing edge with all other configuration effects from $\mathrm{OH} 3 \mathrm{~A}$ to $\mathrm{OH} 9$ still included.

OH11A switches the rotor noise source from the F7/A7 design to the Historical Baseline F31/A31 design. The experimental data for the F31/A31 rotor noise source was provided without a pylon and at zero angle of attack. ${ }^{35}$ Configuration OH11A applied the pylon blowing and AOA effects from the F7A7 data to the F31/A31 data but not the clipping effect as that was already included. Therefore, the new rotor noise source signature was derived from two different experiments. Because OH11A was an uninstalled configuration, three rotors are included together with the baseline airframe sources.

$\mathrm{OH} 12 \mathrm{~A}$ changes only the rotor noise source from that of OH11A, applying the projection ${ }^{14}$ of the best low noise rotor for the 2025 timeframe, the Advanced Quiet Rotor (AQ).

$\mathrm{OH} 13$ and $\mathrm{OH} 14$ installed the AQ together with all the other installation effects at $1.0 \mathrm{D}$ and $1.5 \mathrm{D}$, respectively, on the OREIO. 
This study has endeavored to include as many of the installation effects as possible and, specifically, noise reducing design criteria and some noise reducing technologies. However, only one, albeit extensive, PAA installation effects experiment was available for this study, and high fidelity prediction methods are as yet too limited to apply to a system study. Furthermore, some of the technology assessed in this study, the airframe acoustic liner, while promising as a novel noise reduction technology has only reached the proof-of-concept stage with successful experimental data. Therefore, OH15 is a configuration that is intended to include the estimated effect of further optimization and technology development. Effects are chosen based on what was seen from this study as likely approaches or effects that are promising for further noise reduction. This configuration and the additional effects will be discussed in the following section.

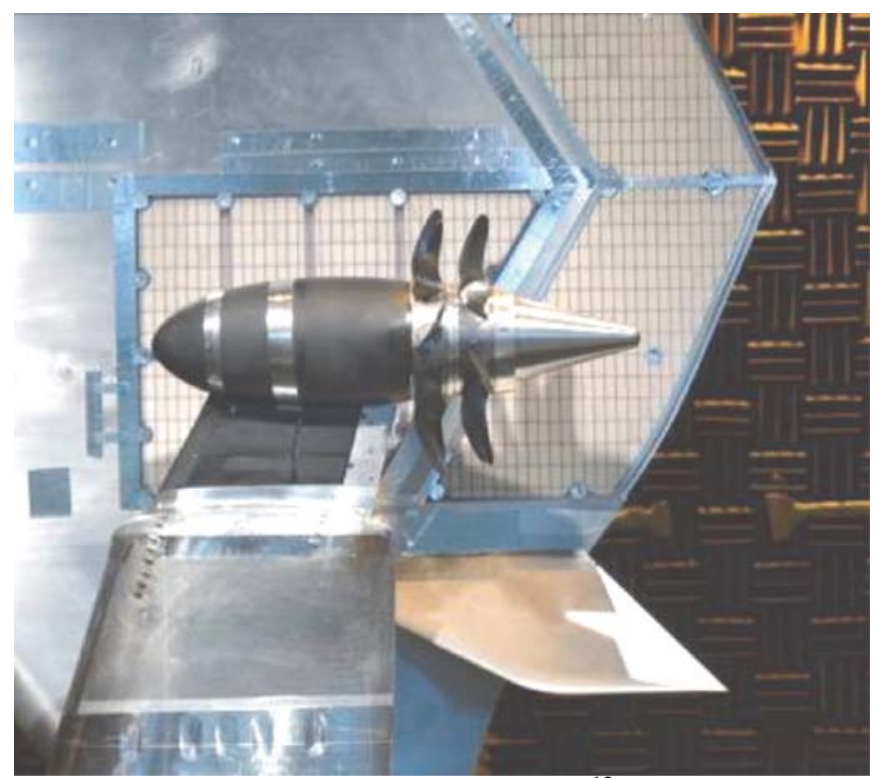

Figure 11. Close up of the HWB experimental configuration ${ }^{13}$. Rotor is at 1.0D. A vertical surface is shown as well as the inserts on each elevon and a third airframe insert that the open rotor is positioned over. 
Table 3. Configuration Definitions.

\begin{tabular}{|c|c|c|c|c|c|c|c|c|}
\hline Configuration & $\begin{array}{l}\text { Description } \\
\text { /Purpose }\end{array}$ & Blade Set & $\begin{array}{c}\text { Engine } \\
\text { Position } \\
\text { (Shielding } \\
\text { Effect) } \\
\end{array}$ & $\begin{array}{l}\text { Included } \\
\text { Effects }\end{array}$ & $\begin{array}{c}\text { Vertical } \\
\text { Type / } \\
\text { Cant } \\
\text { Angle } \\
\end{array}$ & $\begin{array}{c}\text { Elevon } \\
\text { Deflection } \\
\text { Angle }\end{array}$ & $\begin{array}{l}\text { External } \\
\text { Acoustic } \\
\text { Liner }\end{array}$ & $\begin{array}{c}\text { Airframe } \\
\text { Components }\end{array}$ \\
\hline \multicolumn{9}{|c|}{ Isolated Open Rotor Configurations } \\
\hline IRA & $\begin{array}{l}\text { Three isolated } \\
\text { Rotors } \\
\end{array}$ & F7/A7 & N/A & N/A & N/A & N/A & N/A & None \\
\hline IRB & $\begin{array}{c}\text { Adds pylon } \\
\text { blowing }\end{array}$ & F7/A7 & N/A & $\begin{array}{c}\text { Pylon } \\
\text { blowing }\end{array}$ & N/A & N/A & N/A & None \\
\hline IRC & $\begin{array}{l}\text { Adds clipping } \\
\text { of aft rotor }\end{array}$ & F7/A7 & N/A & $\begin{array}{l}\text { Pylon } \\
\text { blowing, } \\
\text { clipping aft } \\
\text { rotor } \\
\end{array}$ & N/A & N/A & N/A & None \\
\hline IR0 & Adds AOA & F7/A7 & N/A & $\begin{array}{c}\text { Pylon } \\
\text { blowing, } \\
\text { clipping aft } \\
\text { rotor, } \\
\text { AOA } \\
\end{array}$ & N/A & N/A & N/A & None \\
\hline \multicolumn{9}{|c|}{ OREIO HWB Aircraft Configurations } \\
\hline OH0 & $\begin{array}{l}\text { Three rotors w/ } \\
\text { airframe } \\
\text { sources, no } \\
\text { shielding }\end{array}$ & F7/A 7 & N/A & $\begin{array}{c}\text { Pylon } \\
\text { blowing, } \\
\text { clipping aft } \\
\text { rotor, AOA }\end{array}$ & N/A & None & None & $\begin{array}{l}\text { Baseline } \\
\text { Airframe } \\
\text { Sources }\end{array}$ \\
\hline OH3A & $\begin{array}{c}\text { Adds shielding } \\
\text { with rotors at } \\
1.0 \mathrm{D}\end{array}$ & F7/A 7 & $1.0 \mathrm{D}$ & “ & N/A & None & None & Baseline \\
\hline OH4 & Adds verticals & F7/A7 & $1.0 \mathrm{D}$ & $" “$ & $\mathrm{~V} 1 / 102^{\circ}$ & None & None & Baseline \\
\hline OH5 & $\begin{array}{c}\text { Increases cant } \\
\text { angle }\end{array}$ & F7/A 7 & $1.0 \mathrm{D}$ & “ & $\mathrm{V} 1 / 120^{\circ}$ & None & None & Baseline \\
\hline OH6 & $\begin{array}{c}\text { Adds effect of } \\
\text { elevon } \\
\text { deflection } \\
\end{array}$ & F7/A 7 & $1.0 \mathrm{D}$ & “ & $\mathrm{V} 1 / 120^{\circ}$ & $\begin{array}{c}-5^{\circ} \mathrm{TO} \\
0^{\circ} \mathrm{AP}\end{array}$ & None & Baseline \\
\hline OH 7 & $\begin{array}{l}\text { Adds elevon } \\
\text { and airframe } \\
\text { acoustic liners }\end{array}$ & F7/A 7 & $1.0 \mathrm{D}$ & “ & $\mathrm{V} 1 / 120^{\circ}$ & $\begin{array}{c}-5^{\circ} \mathrm{TO} \\
0^{\circ} \mathrm{AP}\end{array}$ & broadband & Baseline \\
\hline OH8 & $\begin{array}{c}\text { Increased } \\
\text { elevon } \\
\text { deflection } \\
\end{array}$ & F7/A7 & $1.0 \mathrm{D}$ & “ & $\mathrm{V} 1 / 120^{\circ}$ & $\begin{array}{c}-14^{\circ} \mathrm{TO} \\
0^{\circ} \mathrm{AP}\end{array}$ & broadband & Baseline \\
\hline OH9 & $\begin{array}{l}\text { Low noise } \\
\text { landing gear }\end{array}$ & F7/A7 & $1.0 \mathrm{D}$ & “ & $\mathrm{V} 1 / 120^{\circ}$ & $\begin{array}{c}-14^{\circ} \mathrm{TO} \\
0^{\circ} \mathrm{AP}\end{array}$ & broadband & $\begin{array}{l}\text { Add landing } \\
\text { gear noise } \\
\text { reduction }\end{array}$ \\
\hline OH10 & $\begin{array}{c}\text { Moves rotor } \\
\text { upstream for } \\
\text { added shielding }\end{array}$ & F7/A7 & $1.5 \mathrm{D}$ & $" “$ & $\mathrm{~V} 1 / 120^{\circ}$ & $\begin{array}{c}-14^{\circ} \mathrm{TO} \\
0^{\circ} \mathrm{AP}\end{array}$ & broadband & $\begin{array}{l}\text { Add landing } \\
\text { gear noise } \\
\text { reduction }\end{array}$ \\
\hline OH11A & $\begin{array}{c}\text { Improved blade, } \\
\text { best } 1980 \text { s aero } \\
\text { and noise, no } \\
\text { shielding }\end{array}$ & $\begin{array}{l}\text { Historical } \\
\text { Baseline } \\
\text { F31/A31 }\end{array}$ & N/A & $\begin{array}{l}\text { Pylon } \\
\text { blowing, } \\
\text { AOA }\end{array}$ & N/A & N/A & N/A & Baseline \\
\hline OH12A & $\begin{array}{l}\text { Projected low } \\
\text { noise rotor for } \\
2025, \text { no } \\
\text { shielding } \\
\end{array}$ & $\begin{array}{l}\text { Advanced } \\
\text { Quiet } \\
\text { Rotor }\end{array}$ & N/A & “ & N/A & N/A & N/A & Baseline \\
\hline OH13 & $\begin{array}{c}\text { Advanced Quiet } \\
\text { Rotor installed } \\
\text { at } 1.0 \mathrm{D}\end{array}$ & $\begin{array}{l}\text { Advanced } \\
\text { Quiet } \\
\text { Rotor }\end{array}$ & $1.0 \mathrm{D}$ & “ & $\mathrm{V} 1 / 120^{\circ}$ & $\begin{array}{c}-14^{\circ} \mathrm{TO} \\
0^{\circ} \mathrm{AP}\end{array}$ & broadband & $\begin{array}{l}\text { Add landing } \\
\text { gear noise } \\
\text { reduction }\end{array}$ \\
\hline OH14 & $\begin{array}{l}\text { Advanced Quiet } \\
\text { Rotor, moved } \\
\text { upstream }\end{array}$ & $\begin{array}{l}\text { Advanced } \\
\text { Quiet } \\
\text { Rotor }\end{array}$ & $1.5 \mathrm{D}$ & $"$ & $\mathrm{~V} 1 / 120^{\circ}$ & $\begin{array}{c}-14^{\circ} \mathrm{TO} \\
0^{\circ} \mathrm{AP}\end{array}$ & broadband & $\begin{array}{l}\text { Add landing } \\
\text { gear noise } \\
\text { reduction }\end{array}$ \\
\hline OH15 & $\begin{array}{c}\text { best } 2025 \text { low } \\
\text { noise }\end{array}$ & $\begin{array}{c}\text { Advanced } \\
\text { Quiet } \\
\text { Rotor } \\
\end{array}$ & $1.5 \mathrm{D}$ & Addition & projections & $\begin{array}{l}\text { timated from } \\
\text { developme }\end{array}$ & ptimization a & technology \\
\hline
\end{tabular}




\section{Results}

The configurations in Table 3 are selected in a progressive order to accumulate as many as possible of the real source and installation effects as would actually exist on the OREIO aircraft. The configurations build up to the final configuration and in so doing highlight the impact at an aircraft system noise level of the design parameters and technologies that are identified.

Using the experimental data as described previously with the same flight path and conditions as the OREIO, the calculated EPNLdB levels for three isolated F7/A7 rotors are shown in Table 4. As reported in Czech and Thomas ${ }^{15}$ the pylon blowing in this experimental setup reduced primarily the fundamental tone of the forward rotor. The impact is a reduction of 1 EPNLdB cumulative. The estimated effect of aft rotor clipping when applied to the F7/A7 data together with the pylon blowing was a total reduction of 4.6 EPNLdB, see Table 4 (configuration IRC). An AOA of $7^{\circ}$ was chosen from the experimental database and Table 4 (configuration IR0) shows that the effect is to increase noise by about 2.5 EPNLdB. When adding these three effects, the overall reduction was 2.1 EPNLdB relative to the beginning baseline IRA configuration.

As has already been emphasized previously, blade design technology has advanced considerably since the UDF ${ }^{\circledR}$ flight demonstrator engine using the F7/A7 blade. Table 5 shows the impact at the uninstalled aircraft level for the three blade designs of this study, the Legacy F7/A7 on configuration OH0, the Historical Baseline F31/A31 on configuration OH11A, and the Advanced Quiet Rotor on configuration OH12A. The uninstalled aircraft level includes the three engines and the airframe noise sources with all the aircraft level effects from angle of attack, aircraft velocity and flight path, however, the installation effects, including shielding, are not included. In this way, the source noise effects can be largely quantified separately from the installation effects. As expected, the noise reduction from the F7/A7 (OH0) to the F31/A31 (OH11A) is very large at a cumulative 29.0 EPNLdB. The noise reduction from the F31/A31 to the Advanced Quiet Rotor (OH12A) is a cumulative 14.2 EPNLdB, again another large reduction due to open rotor blade design technology.

The next sequence of aircraft system level impacts highlights the installation effects produced by integration with the airframe and is shown in Fig.12 graphically with tabulated values in Table 6. These noise levels were determined using the F7/A7 rotor design and experimental data. Installation of the three open rotors at a location upstream of the trailing edge of 1.0D accounts for the large 18.9 EPNLdB cumulative reduction from OH0 to $\mathrm{OH} 3 \mathrm{~A}$. With the F7/A7 rotor, this large impact is due to the substantial shielding by the HWB planform both from the forward shield surface of the OREIO and the smaller 1.0D aft shield dimension.

Table 4. EPNLdB Impact of Effects Applied to Three Isolated F7/A7 Rotors

\begin{tabular}{|c|c|c|c|c|}
\hline Configuration & Flyover & Sideline & Approach & CUM rel. IRA \\
\hline IRA & 112.2 & 113.1 & 104.7 & 0.0 \\
\hline IRB & 112.1 & 113.0 & 103.9 & -1.0 \\
\hline IRC & 110.6 & 111.9 & 102.9 & -4.6 \\
\hline IR0 & 111.6 & 112.7 & 103.6 & -2.1 \\
\hline
\end{tabular}

Table 5. Impact of Rotor Blade Technology at the Isolated Level, Engine and Airframe Sources

\begin{tabular}{|c|c|c|c|c|}
\hline Configuration & Flyover & Sideline & Approach & CUM rel. Stage 4 \\
\hline OH0 / LY & 111.6 & 112.7 & 104.0 & 32.9 \\
\hline OH11A / HB & 99.7 & 103.1 & 96.5 & 3.9 \\
\hline OH12A / AQ & 93.8 & 97.1 & 94.2 & -10.3 \\
\hline
\end{tabular}


Table 6. System Level Impacts of Installation Effects with the F7/A7 as Rotor Noise Source, EPNLdB

\begin{tabular}{|c|c|c|c|c|}
\hline Configuration & Flyover & Sideline & Approach & $\begin{array}{c}\text { CUM rel. } \\
\text { Stage 4 }\end{array}$ \\
\hline OH0 & 111.6 & 112.7 & 104.0 & 32.9 \\
\hline OH3A & 102.7 & 108.7 & 98.0 & 14.0 \\
\hline OH4 & 101.7 & 108.0 & 97.7 & 11.9 \\
\hline OH5 & 100.9 & 107.6 & 97.6 & 10.7 \\
\hline OH6 & 100.9 & 107.5 & 97.6 & 10.6 \\
\hline OH7 & 100.4 & 107.4 & 97.5 & 9.9 \\
\hline OH8 & 100.0 & 107.1 & 97.5 & 9.2 \\
\hline OH9 & 100.0 & 107.1 & 96.3 & 8.0 \\
\hline OH10 & 97.8 & 104.1 & 96.5 & 3.0 \\
\hline
\end{tabular}

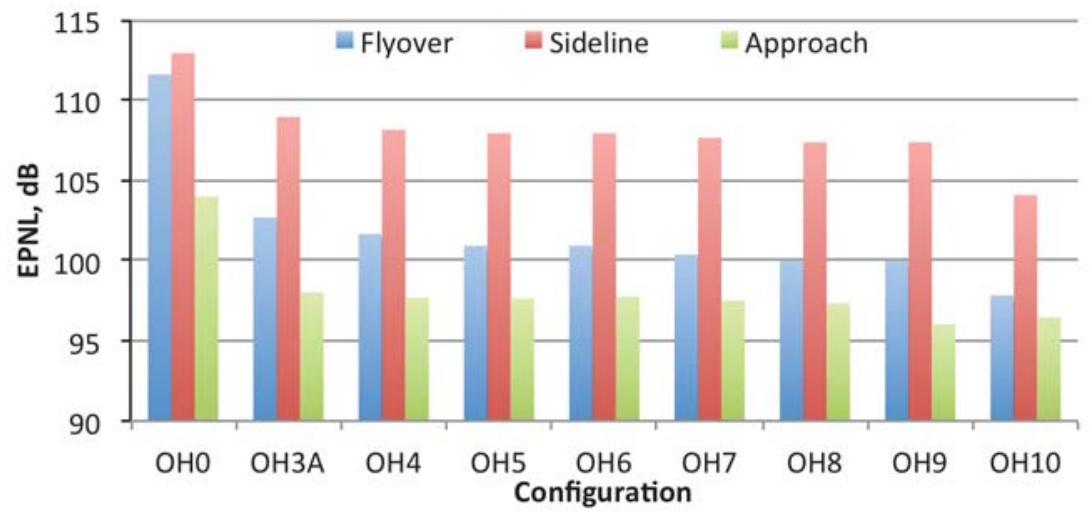

Figure 12. Graphically plotted system level impacts of installation effects with the F7/A7 as the rotor noise source.

The effect of the vertical tail surfaces were added with configuration $\mathrm{OH} 4$ using the baseline vertical configuration V1 at a cant angle of $102^{\circ} .{ }^{14,21}$ The vertical surfaces create the possibility of multiple acoustic propagation paths involving both shielding and reflection. Based on the experimental data using the F7/A7 as the rotor noise source and the analysis process described above, the effect of the verticals contributes to noise reduction by a significant $2.1 \mathrm{EPNLdB}$ cumulative. By increasing the vertical cant angle to $120^{\circ}$ (Configuration OH5) results in an additional 1.2 EPNLdB cumulative of noise reduction. It is important to note the results of the impact from the verticals and design parameters for the verticals is influenced by several factors including the rotor noise source for which the analysis is being performed. Using the experimental data and the analysis process described here and in Bahr et al. ${ }^{23}$ and Guo et al. ${ }^{24}$ can result in a differing noise reduction magnitudes, particularly if the source noise is produced from a different rotor design (with a lower overall noise level and different directivity). If the effect of the vertical is calculated with the rotor noise source from the Advanced Quiet Rotor the resulting impact could likely be less than the $3.3 \mathrm{~dB}$ shown for the F7/A7. Similarly, Guo ${ }^{22}$ reports such a conclusion regarding the effect of the verticals having calculated magnitudes that are considerably less than those reported here. When Guo considers the vehicle performance impact of the verticals he recommends not including the verticals.

Configuration $\mathrm{OH} 6$ added the deflection of the elevon of $-5^{\circ}$ (up) on takeoff only. The elevon is held at zero degrees deflection on approach. Experimental data shows a small but definite increase in shielding from the deflection of the elevon to $-5^{\circ}$. However, at a system level for this flight path the impact was negligible at only 0.1 EPNLdB cumulative decrease. 
The effect of acoustic liner applied to the airframe was considered in Configuration OH7. A broadband acoustic liner was applied to the upper surface of both the elevon and airframe in the vicinity of the rotor. The impact at a system level is a significant $0.7 \mathrm{EPNLdB}$ cumulative decrease.

By extrapolating the experimental data to account for the proper elevon deflection angle of $-14^{\circ}$ (at takeoff only), configuration $\mathrm{OH} 8$ now shows that elevon deflection had an additional noise reduction of $0.7 \mathrm{~dB}$ relative to $\mathrm{OH} 7$. The effect of the elevon is attributable to the fact that, by geometry, the elevon deflection increases the shielded of the rotor and more so in the polar angle and hence impacts the flyover and sideline levels more than the approach level as can be seen in Table 6.

The application of landing gear noise reduction at the system level (OH9) amounted to 1.2 EPNLdB cumulative, and this reduction is found only for the approach condition. The landing gear noise reduction is the result of the projected low noise gear design. Additional reductions will be presented $(\mathrm{OH} 15)$ that are a result of reducing the local flow velocity at the gear assemblies.

Configuration $\mathrm{OH} 10$ shows the impact, including all effects, of moving the engine and rotor location 0.5D further upstream, to a total of $1.5 \mathrm{D}$ upstream of the trailing edge. As a primary variable, this impact is large and added another 5.0 EPNLdB cumulative of noise reduction. Noise data scaled to the approach condition (thrust of $3200 \mathrm{lbs}$ ) for the $\mathrm{OH} 10$ configuration was not available. The noise data at 13,328 lbs of thrust were used to estimate the noise at the approach condition by applying a uniform noise level decrease spectrally for all polar and azimuthal locations, recognizing that this is a gross estimation of a complex noise field. Note that the approach noise shows an increase of $0.2 \mathrm{~dB}$ due to the integration range of the EPNL metric; the airframe sources have a longer integration time compared to the rotor sources which have been reduced further with the additional shielding.

Shielding by the planform is the single largest noise reduction from installation with the critical parameter being the aft shield area as measured by the location upstream of the trailing edge. Figure 13 shows the dependence of noise on the distance upstream of the trailing edge for both the off-center rotor location (see Fig. 11) and the centerline location.

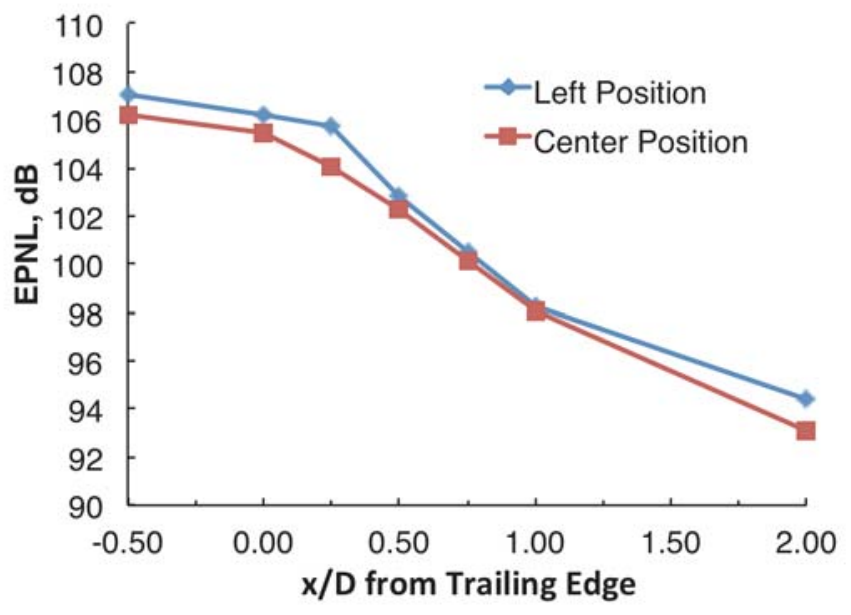

Figure 13. EPNLdB impact of open rotor noise (F7A7 rotor noise source) as function of location relative to the trailing edge for the flyover condition.

In total, with the F7/A7 as the rotor noise source, Table 6 shows that almost 30 EPNLdB cumulative of noise reduction is possible for a fully installed configuration with the rotor at $1.5 \mathrm{D}$. Clearly most of that noise reduction is from shielding ( $24 \mathrm{EPNLdB})$ but on the order of $6 \mathrm{EPNLdB}$ cumulative is possible from a variety of additional installation effects other than the shielding by the basic planform itself and from airframe source noise reduction. These additional impacts are a critical element to the achievement of an aggressive aircraft system goal.

The next sequence calculates the impact of the Advanced Quiet (AQ) rotor installation with the ORIEO airframe. Table 7 gives the noise levels at the three certification points as well as the cumulative levels for the final four configurations: three AQ rotors without shielding but with airframe sources $(\mathrm{OH} 12 \mathrm{~A})$, three AQ rotors installed at 1.0D upstream of the trailing edge $(\mathrm{OH} 13)$, three $\mathrm{AQ}$ rotors at $1.5 \mathrm{D}$ upstream $(\mathrm{OH} 14)$ and $\mathrm{OH} 15$ which includes the additional noise reduction approaches identified in Table 8. The purpose is to show what might be possible with the 
development of the additional list of noise reduction approaches. The separate component level EPNL reduction for each approach relative to $\mathrm{OH} 14$ is given in the right most column of Table 8 . The last row of Table 8 represents at a system level the total EPNLdB effect of considering all the reductions at once. Figure 14 shows graphically the same information as Table 7.

Table 7. System Level Impacts Using the Open Rotor Noise Source Levels of the Advanced Quiet Rotor.

\begin{tabular}{|c|c|c|c|c|}
\hline Configuration & Flyover & Sideline & Approach & $\begin{array}{c}\text { Cumulative rel. } \\
\text { Stage 4 }\end{array}$ \\
\hline OH12A & 93.8 & 97.1 & 94.2 & -10.3 \\
\hline OH13 & 86.5 & 92.9 & 89.9 & -26.0 \\
\hline OH14 & 84.1 & 90.7 & 89.8 & -30.8 \\
\hline OH15 & 82.4 & 88.7 & 86.3 & -38.0 \\
\hline
\end{tabular}

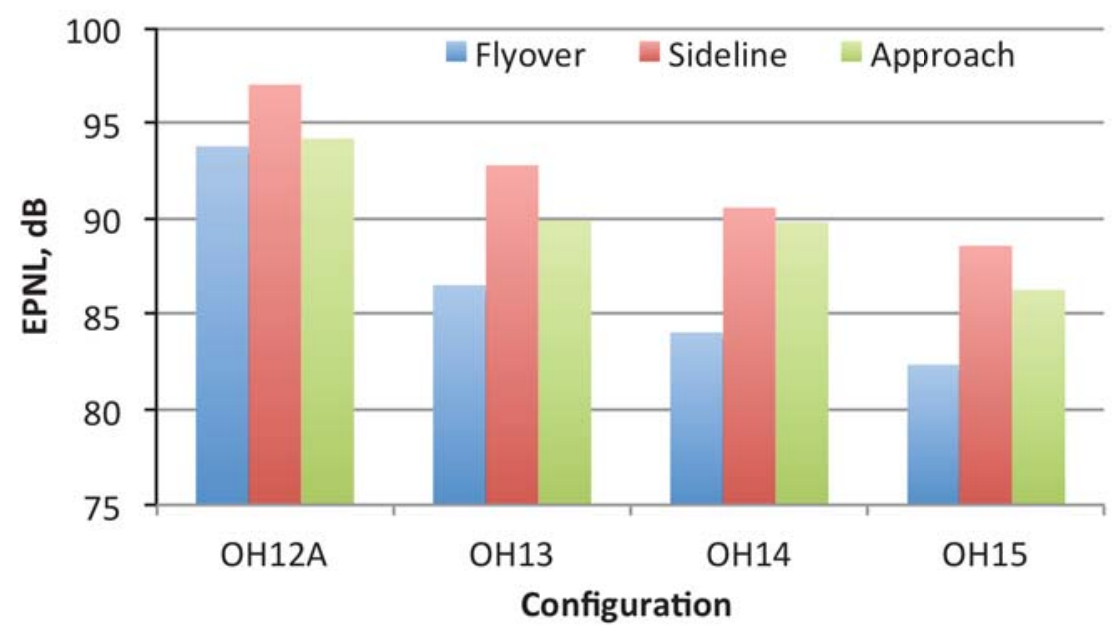

Figure 14. Graphically plotted system level impacts of installation with the open rotor noise levels of the Advanced Quiet rotor.

In Table 9, the noise levels for the same four final configurations are given, except that the rotor shielding effect was determined using a tone matching process rather than taking a direct difference between shielded and unshielded results as was done for the results in Table 7. Either method can be used in the process of applying the shielding effect from the experimental database (obtained with the F7/A7 rotor) to the rotor and condition necessary for an OREIO configuration. The tone matching process is proposed to better capture tone scattering physics compared to the direct difference method and is discussed in Bahr et al. ${ }^{23}$ and Guo. ${ }^{24}$ Both results are shown here for comparison and can also indicate the variability that can be expected as a result of the choice of data processing strategy and detailed methodology. Configuration OH12A has a level of $10.3 \mathrm{~dB}$ cumulative below Stage 4, which is a very low level for an open rotor aircraft as has already been discussed. Now consider the shielding effect if installed at 1.0D upstream and with the additional installation effects the overall result is the level of $26.0 \mathrm{~dB}$ below Stage 4, or $15.7 \mathrm{~dB}$ below the isolated noise level of OH12A. If installed with $1.5 \mathrm{D}$ of shielding then the system level drops an additional $4.8 \mathrm{~dB}$ to a total of $30.8 \mathrm{~dB}$ below Stage 4 . The same results obtained using the tone matching process are within less than 1.7 EPNLdB of the results from using the direct difference method and provides additional confidence in the magnitude of these findings. 
Table 8. Projected Additional Effects from Further Optimization and Technology Development

\begin{tabular}{|l|l|c|}
\hline \multicolumn{1}{|c|}{ Effect Included in OH14 } & \multicolumn{1}{|c|}{ Reasoning } & $\begin{array}{c}\text { Aircraft EPNLdB } \\
\text { effect rel. OH14 }\end{array}$ \\
\hline $\begin{array}{l}\text { Lower approach speed by 10 } \\
\text { knots }\end{array}$ & $\begin{array}{l}\text { Reasonable reduction from including lower } \\
\text { approach speed in design criteria }\end{array}$ & -1.6 \\
\hline Airframe acoustic liner & $\begin{array}{l}\text { Continued development toward optimized design, } \\
\text { including low drag capability. Estimate of 1dB } \\
\text { spectral reduction of open rotor noise }\end{array}$ & -1.8 \\
\hline $\begin{array}{l}\text { Optimizing elevon and vertical } \\
\text { shielding }\end{array}$ & $\begin{array}{l}\text { Optimizing size, position, and edge effects. } \\
\text { Estimate of 1dB spectral reduction of open rotor } \\
\text { noise }\end{array}$ & -1.8 \\
\hline $\begin{array}{l}\text { Additional landing gear noise } \\
\text { reduction }\end{array}$ & $\begin{array}{l}\text { Additional noise reduction through local shape } \\
\text { design of the HWB airframe to control local } \\
\text { velocity into the landing gear. Estimate a 6.3\% } \\
\text { reduction in local flow velocity into landing gear }\end{array}$ & -1.2 \\
\hline $\begin{array}{l}\text { Krueger slat leading edge noise } \\
\text { reduction }\end{array}$ & $\begin{array}{l}\text { Only a baseline estimate of Krueger noise is used, } \\
\text { projection for noise reduction design from research } \\
\text { and development effort. Estimate of 2dB spectral } \\
\text { reduction for Krueger slat noise component }\end{array}$ & -0.6 \\
\hline $\begin{array}{l}\text { Total System Level Reduction } \\
\text { Possible (OH15 rel. OH14) }\end{array}$ & & -7.2 \\
\hline
\end{tabular}

Table 9. System Level Impacts Using Tone Matching Process ${ }^{23}$ to Account for PAA Shielding Effects

\begin{tabular}{|c|c|c|c|c|}
\hline Configuration & Flyover & Sideline & Approach & $\begin{array}{c}\text { Cumulative rel. } \\
\text { Stage 4 }\end{array}$ \\
\hline OH12A & 96.1 & 96.7 & 94.0 & -8.6 \\
\hline OH13 & 87.8 & 90.9 & 89.8 & -26.9 \\
\hline OH14 & 85.8 & 89.9 & 89.7 & -30.0 \\
\hline OH15 & 84.1 & 87.9 & 86.0 & -37.4 \\
\hline
\end{tabular}

Source noise component ranking and duration factor observations are made by examining the time dependent tone corrected perceived noise levels (PNLT). Figure 15a-c are the PNLT plots for the uninstalled AQ rotor while Figs. 16a-c shows the PNLT plots for the final HWB configuration with the AQ rotor installed at 1.5D.

For the approach condition shown in Fig. 15a, the total airframe noise is higher than the engine but not significantly. The main landing gear and Krueger slat sources are only slightly higher in peak PNLT level than the rotor component. For the installed AQ rotor approach condition in Fig. 16a, where the three AQ rotors are 1.5D upstream of the trailing edge and the landing gear noise reduction was applied, the main landing gear is still the dominant source. The rotor and Krueger slat noise peak levels are reduced to nearly that of the trailing edge peak level. The trailing edge noise prediction method is of the lowest fidelity and this source has not historically been of concern compared to the other more dominant aircraft sources. With the dramatic reductions projected for rotor, landing gear and slat noise, the other sources such as trailing edge and core noise are becoming competitive. Due to past insignificance of those sources, prediction methods tend not to be as well developed or validated, but with these findings some more attention is necessary to accurately predict trailing edge and engine core sources.

At sideline condition the rotor is the dominant noise source as shown in Fig. 15b for OH12A and Fig. 16b for OH14. Peak noise level is held for a longer time of more than 10 seconds. For times greater than about 115 seconds, the PNLT gently falls off. The rotor noise data required for these times were extrapolated from the measurements. ${ }^{22}$ 
With the fully installed configuration, Fig. 16b, the level of peak rotor noise and hence the overall noise level is greatly reduced and is lengthened over an even longer time period before a single peak emerges (approximately time $=110$ seconds) as the rotor becomes more exposed with the passing of the rotor over the observer.

The flyover condition creates a more effective shielding of the rotor noise compared to sideline and the result is a more substantial $10 \mathrm{~dB}$ reduction in the peak PNLT level as seen when comparing Fig. 15c and Fig. 16c. What is also seen with the OH14 configuration is that with the shielding reducing the rotor noise, the rotor peak PNLT is approaching (within about $7 \mathrm{~dB}$ ) the airframe component peaks for the Krueger slat and trailing edge as well as the engine core. For comparison with Figs. 15c and 16c, Figs. 17a and 17b shows the flyover condition results obtained from using the tone matching process to define the rotor installation effect. (Note OH12A includes installation effects for pylon blowing and AOA but not airframe shielding, whereas OH14 includes all installation effects.) The rotor noise spikes in Figs. 15c and 16c, for time < 115 seconds, are significantly minimized in Figs. 17a and 17b, respectively. Installed open rotor tone noise is a result of phase, amplitude, and directivity of individual tones, which can affect the far-field overall levels and directivity. ${ }^{23,24}$ The direct difference processing does not address individual tone shielding effects, however it does indirectly address tones by $1 / 3^{\text {rd }}$ octave band suppression.

For several key configurations, Fig. 18 shows final levels graphically relative to Stage 4 and to the NASA N+2 noise goal of $42 \mathrm{EPNLdB}$. The Historical Baseline rotor is assessed at 3.9 EPNLdB above Stage 4 and represents technology originating over a decade ago. The configuration with the Advanced Quiet Rotor (OH13) assesses at 26.0 EPNLdB below Stage 4 and represents an aggressive configuration concept including the Advanced Quiet Rotor, engines installed 1.0D upstream of the trailing edge and additional noise reduction technologies. Maturing the OH13 concept and technologies could be considered a difficult challenge for the 2025 timeframe. At the same time, a level of $26.0 \mathrm{~dB}$ for an open rotor aircraft would definitely be a breakthrough. Configuration $\mathrm{OH} 14$ at 30.8 EPNLdB is within $11 \mathrm{~dB}$ of the $\mathrm{N}+2$ goal but requires the engines to be installed at $1.5 \mathrm{D}$ upstream of the trailing edge with the associated challenges that are yet to be addressed. Configuration OH15 is only an estimated projection of the potential impact of additional optimization and effects identified in Table 8. The value of the OH15 estimated projection is that it is possible to achieve a level close to the NASA N+2 goal with the technologies and parameters that have already been identified. 


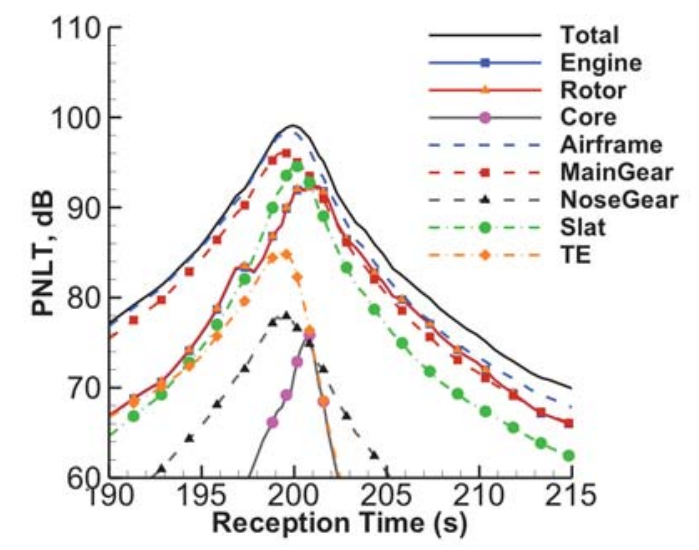

Figure 15a. OH12A: AQ Rotor \& airframe sources but no shielding. Approach Condition.

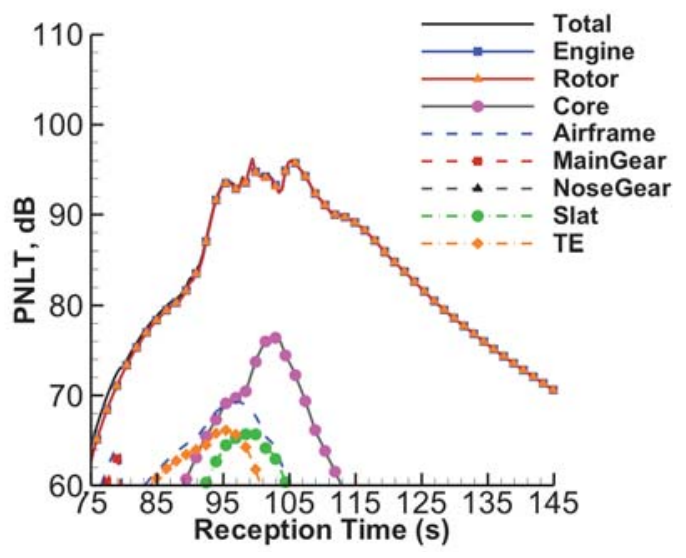

Figure 15b. OH12A: AQ Rotor \& airframe sources but no shielding. Sideline condition.

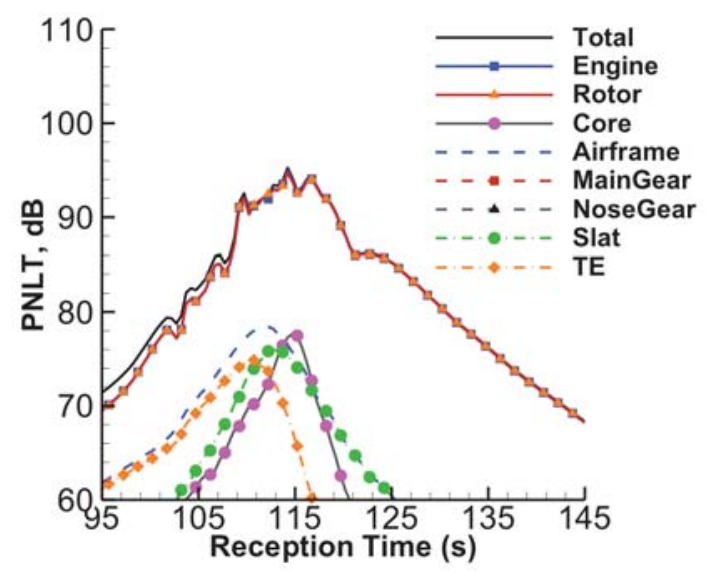

Figure 15c. OH12A: AQ Rotor \& airframe sources but no shielding. Flyover condition.

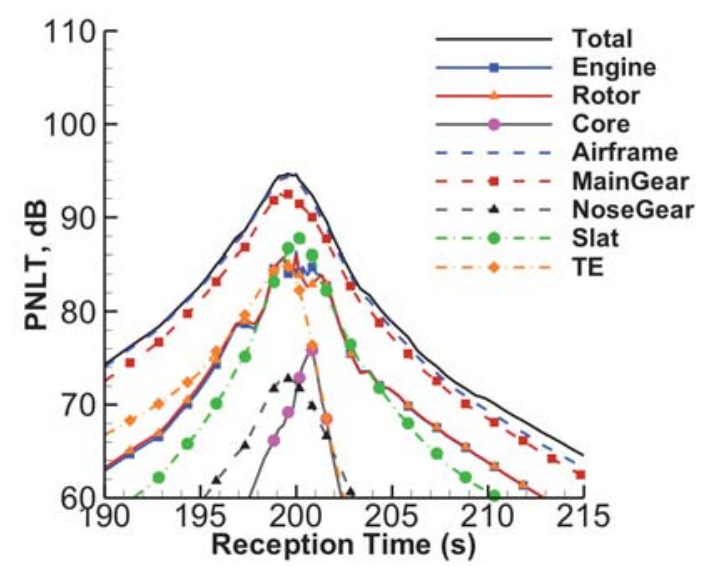

Figure 16a. OH14: Installed HWB with $A Q$ rotor at 1.5D. Approach Condition.

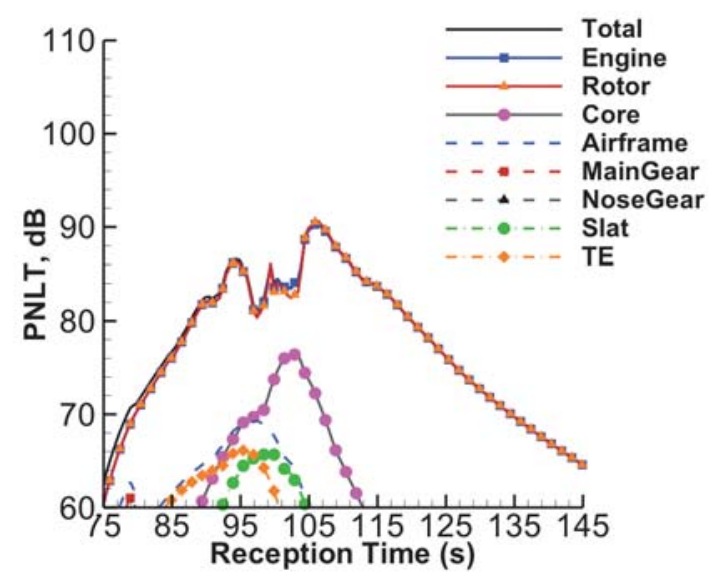

Figure 16b. OH14: Installed HWB with AQ rotor at $1.5 \mathrm{D}$. Sideline condition.

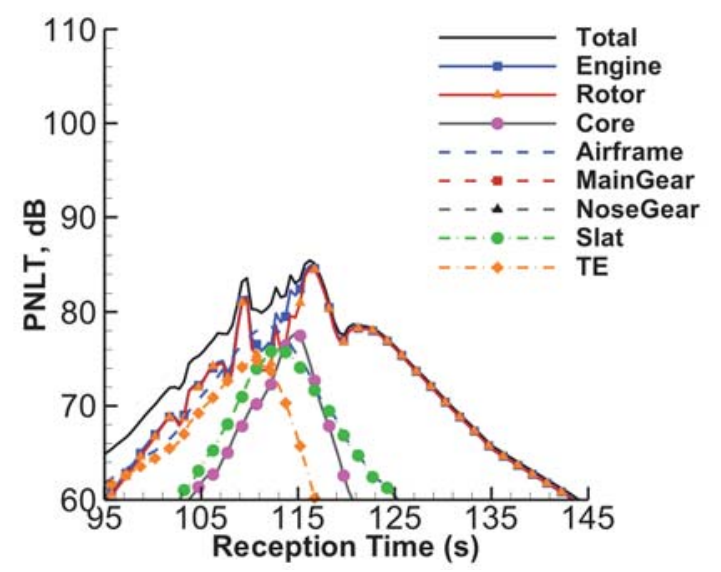

Figure 16c. OH14: Installed HWB with $A Q$ rotor at 1.5D. Flyover condition. 


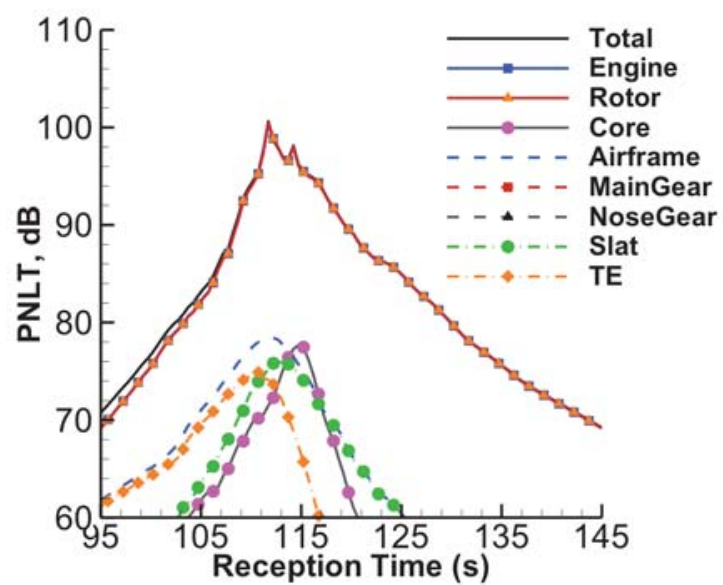

Figure 17a. OH12A with AQ rotor, no shielding, at flyover condition. TM process.

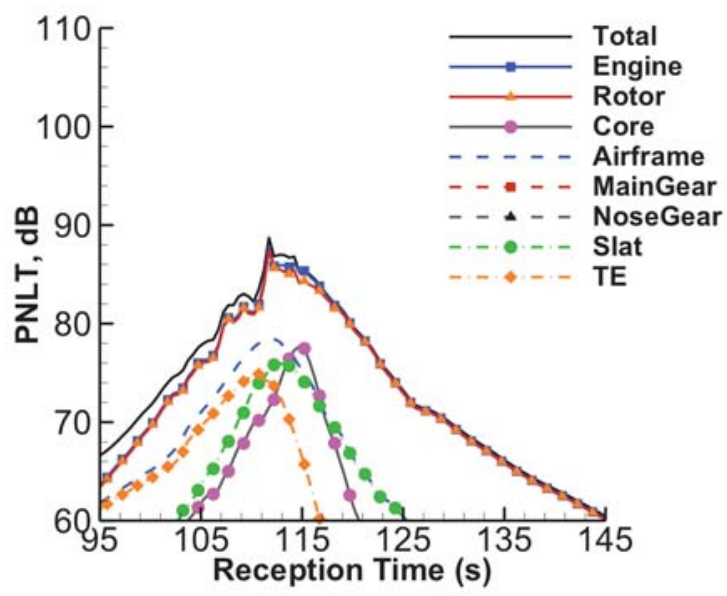

Figure 17b. OH14 Installed HWB with $A Q$ rotor at 1.5D, flyover condition. TM process.

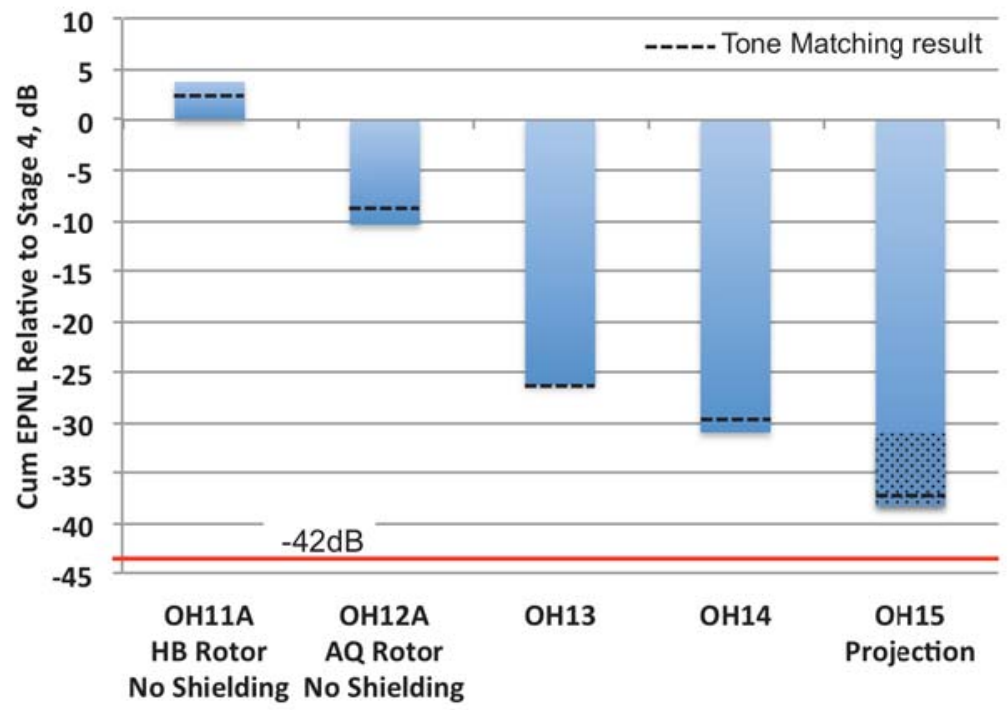

Figure 18. Final summary of system level assessment values.

\section{Conclusion}

Open rotor propulsion systems have long held the promise of a further step in fuel burn reduction and have also been challenged by relatively high levels of noise among other integration issues. Recent campaigns of development have produced validated high performance blade designs with system noise levels of 16.8 EPNLdB below Stage 4 when assessed on a conventional tail mount aircraft. While these levels are well below Stage 4 they are far short of NASA's aggressive N+2 noise goal. Projecting into the future, when further advancements in open rotor blade design are anticipated and are combined with installation on a HWB aircraft concept, this study has shown that it may be possible to reach low noise levels, even approaching close to the NASA N+2 goal of 42 EPNLdB cumulative below Stage 4. Installation effects primarily from shielding can account for 20 EPNLdB of the projected system noise reduction when accounting for 1.5 rotor diameters of shielding area downstream of the rotor. Optimization of the shielding effectiveness of the rotor and aircraft integration is a promising area of development. This optimization can include rotor design to tailor directivity, layout of the airframe planform and control surfaces to maximize shielding, and the development of technologies that can impact propagation paths such as the airframe 
acoustic liners for increased shielding effectiveness. The impacts identified in this study, based on experimental work supporting this study, indicate that it may be possible for advancements in shielding effectiveness and other optimization approaches to account for an additional 7.2 EPNLdB cumulative at the aircraft system level.

This study has clearly focused on the noise goal of the aircraft concept and has not addressed the performance impact of the parameters investigated or the additional technologies proposed. In that context, this study is a pathfinding type study that has shown the potential technical path for an open rotor aircraft concept to achieve unprecedented low community noise levels that would be a genuine aeronautics breakthrough. A multidisciplinary design is obviously needed before assessing the noise of this concept within a balanced aircraft design process. A broader range of vehicle level objectives need to be included in such a design process such as interior noise and propulsion aerodynamic integration which is integral to determining the maximum upstream location of the rotor on the HWB airframe. An alternative to an upstream location of the engine is the approach of adding an extension downstream of the airframe specifically as a shield and perhaps integrated with the control surfaces. In addition to such a design process, this study also shows that while there is large potential for noise reduction there is also still much work to do in developing the understanding and prediction methods for the critical propulsion airframe aeroacoustic installation effects, particularly scattering of complex tonal sources.

\section{Acknowledgments}

The authors thank the NASA Environmentally Responsible Aviation Project, Dr. Fay Collier, Project Manager, for funding this research.

\section{References}

${ }^{1}$ Liebeck, R.H., "Design of the Blended-Wing-Body Subsonic Transport," AIAA Paper No. 2002-0002.

${ }^{2}$ Hoff, G.E., et al, "Experimental Performance and Acoustic Investigation of Modern, Counterrotating Blade Concepts," NASA Contractor Report 185158, January, 1990.

${ }^{3}$ Janardan, B.A. and Gliebe, P.R., "Acoustic Characteristics of Counterrotating Unducted Fans from Model Scale Tests," Journal of Aircraft, 27(3):268-275, March 1990.

${ }^{4}$ Woodward, R.P., "Noise of a Model High Speed Counterrotation Propeller at Simulated Takeoff/Approach Conditions (F7/A7)," AIAA Paper 87-2657, October, 1987.

${ }^{5}$ Woodward, R.P. and Gordon, E.B., "Noise of a Model Counterrotation Propeller With Reduced Aft Rotor Diameter at Simulated Takeoff/Approach Conditions," AIAA Paper 88-0263, January, 1988.

${ }^{6}$ Shivashankara, B., Johnson, D., and Cuthbertson, R., "Installation Effection on Counter Rotation Propeller Noise," AIAA Paper 90-4023, October, 1990.

${ }^{7}$ Woodward, R.P. and Hughes, C.E., "Noise of a Model Counterrotation Propeller With Simulated Fuselage and Support Pylon at Takeoff/Approach Conditions," AIAA Paper 89-1143, April, 1989.

${ }^{8}$ Chapman, D.C., Fleury, R.E. and Smith, D.E., “ Testing of the 578-DX Propfan Propulsion System," AIAA Paper 89-2581, July 1989.

${ }^{9}$ Harris, R.W. and Cuthbertson, R.D., "UDF ${ }^{\mathrm{TM}} / 727$ Flight Test Program,” AIAA Paper 87-1733, June, 1987.

${ }^{10}$ Nichols, H.E. “UDF Engine/MD-80 Flight Test Program,” AIAA Paper 88-2805, July 1988.

${ }^{11}$ Bowles, M.D., "The 'Apollo' of Aeronautics, NASA's Aircraft Energy Efficiency Program," NASA SP-2009$574,2010$.

${ }^{12}$ Pitera, D.M., DeHaan, M., Brown, D., Kawai, R.T., Hollowell, S., Camacho, P., Bruns, D., and Rawden, B.K., "Hybrid Wing Body Concept Development with Open Rotor Engine Integration," NASA CR-2011-217303, November, 2011.

${ }^{13}$ Collier, F.S., "Environmentally Responsible Aviation (ERA) Project," presentation at the Third NASA Fundamental Aeronautics Program Annual Meeting, September 29-October 1, 2009, Atlanta, Georgia.

${ }^{14}$ Van Zante, D., Berton, J.J., and Envia, E., private communication, 2012.

15 Czech, M.J., and Thomas, R.H., "Open Rotor Aeroacoustic Installation Effects for Conventional and Unconventional Airframes," AIAA Paper 2013-2185, presented at the $19^{\text {th }}$ AIAA/CEAS Aeroacoustics Conference Berlin, Germany, 2013.

${ }^{16}$ Van Zante, D.E., "The NASA Environmentally Responsible Aviation Project/General Electric Open Rotor Test Campaign,” AIAA 2013-415, January, 2013.

${ }^{17}$ Guynn, M., Berton, J., Hendricks, E., Tong, M., Haller, W., and Thurman, D., "Initial Assessment of Open Rotor Propulsion Applied to an Advanced Single-Aisle Aircraft," AIAA Paper 2011-7058, 2011.

${ }^{18}$ Hendricks, E.S., Berton, J.J., Haller, W.J., Tong, M.T., and Guynn, M.D., "Updated Assessments of an Open Rotor Airplane Using Advanced Blade Designs," AIAA Paper No. 2013-3628. 
${ }^{19}$ Khalid, S.A., Wojno, J.P., Breeze-Stringfellow, A., Lurie, D.P., Wood, T.H., Ramakrishnan, K., and Paliath, U., “Open Rotor Designs for Low Noise and High Efficiency," Proceedings of ASME Turbo Expo 2013, GT201394736, June 3-7, 2013.

${ }^{20}$ Bonet J. T., Schellenger H. G., Rawdon B. K., Elmer K. R., Wakayama S. R., Brown D. \& Guo Y. P. "Environmentally Responsible Aviation (ERA) Project - N+2 Advanced Vehicle Concepts Study and Conceptual Design of Subscale Test Vehicle (STV),”NASA/CR-2013-216519, 2013.

${ }^{21}$ Bonet, J.T., "Boeing ERA N+2 Advanced Vehicle Concept Results," invited presentation at the 50 ${ }^{\text {th }}$ AIAA Aerospace Sciences Meeting, Nashville, TN, January 11, 2012.

${ }^{22}$ Guo, Y., and Thomas, R.H., "System Noise Assessment of Blended-Wing-Body Aircraft with Open Rotor Propulsion," SciTech Conference (National Harbor, Maryland), American Institute of Aeronautics and Astronautics, Reston, VA, 2014, (submitted for publication).

${ }^{23}$ Bahr, C.J., Thomas, R.H., Lopes, L.V., Burley, C.L., and Van Zante, D.E., "Open Rotor Tone Shielding Methods for System Noise Assessments Using Multiple Databases," SciTech Conference (National Harbor, Maryland), American Institute of Aeronautics and Astronautics, Reston, VA, 2014, (submitted for publication).

${ }^{24}$ Guo, Y., Czech, M.J., and Thomas, R.H., "Open Rotor Noise Shielding by Blended-Wing-Body Aircraft," SciTech Conference (National Harbor, Maryland), American Institute of Aeronautics and Astronautics, Reston, VA, 2014, (submitted for publication).

${ }^{25}$ Thomas, R.H., Burley, C.L., and Olson, E.D., " Hybrid Wing Body Aircraft System Noise Assessment with Propulsion Airframe Aeroacoustic Experiments," International Journal of Aeroacoustics, Vol. 11, Number 3+4, 2012.

${ }^{26}$ Czech, M.J., Thomas, R.H., and Elkoby, R., "Propulsion Airframe Aeroacoustic Integration Effects for a Hybrid Wing Body Aircraft Configuration," International Journal of Aeroacoustics, Vol.11, Number 3+4, 2012.

${ }^{27}$ Lopes, L.V., Burley, C.L., "Design of the Next Generation Aircraft Noise Prediction Program: ANOPP2," AIAA Paper 2011-2854, $17^{\text {th }}$ AIAA/CEAS Aeroacoustics Conference, Portland, Oregon, June 5-8, 2011.

${ }^{28}$ Zorumski, William E., “Aircraft Noise Prediction Program Theoretical Manual,” NASA TM-83199, 1982.

${ }^{29}$ Lytle, J.K., “The Numerical Propulsion System Simulation: An Overview,” NASA TM 209915, 2000.

${ }^{30}$ Guo, Y., "An Improved Landing Gear Noise Prediction Scheme," NASA/CR NAS1-NNL04AA11B Task NNL06AB63T, The Boeing Company, Huntington Beach, CA, November 2006.

31 Sen, R., Hardy, B., Yamamoto, K., Guo, Y., Miller, G. "Airframe Noise Sub-component Definition and Model,” Boeing Commercial Airplane Company, NASA/CR-2004-213255, September 2004.

${ }^{32}$ Fink, M., "Airframe Noise Prediction Method," FAA-RD 77-29, U.S. Department of Transportation, Federal Aviation Administration, 1977.

${ }^{33}$ Fink, M., "Noise Component Method for Airframe Noise," AIAA Journal of Aircraft, Vol. 16, No. 10, 1979, pp. 659-665.

34 Emmerling, J. J., Kazin, S. B., and Matta, R. K., "Core Engine Noise Control Program. Volume III, Supplement 1 - Prediction Methods," FAA-RD-74-125, III-I, Mar. 1976. (Available from DTIC as AD A030 376).

${ }^{35}$ Van Zante, D., Gazzaniga, J., Eliott, D., and Woodward, R., “An Open Rotor Test Case: F31/A31 Historical Baseline Blade Set,” ISABE 2011-1310, Gothengurg, Sweden, September, 2011.

${ }^{36}$ U.S. Code of Federal Regulations, Title 14, Chapter I, Part 36. Noise Standards: Aircraft Type and Airworthiness Certification. January 1, 2011.

${ }^{37}$ Berton, J.J., Envia, E., and Burley, C.L., “An Analytical Assessment of NASA's N+1 Subsonic Fixed Wing Project Noise Goal," AIAA Paper No. 2009-3144, presented at the $15^{\text {th }}$ AIAA/CEAS Aeroacoustics Conference, Miami, FL, May, 2009.

${ }^{38}$ Humphreys, W.M., and Brooks, T.F., "Noise Spectra and Directivity For a Scale-Model Landing Gear," AIAA Paper 2007-3458, 2007.

${ }^{39}$ Piet, J.F., Davy, R., Elias, G., Siller, H.A., Chow, L.C., Seror, C., and Laporte, F., "Flight Test Investigation of Add-On Treatments to Reduce Aircraft Airframe Noise," AIAA Paper 2005-3007.

${ }^{40}$ Qualye, A., Dowling, A., Babinsky, H., Graham, W., and Sijtsma, P., "Landing Gear for a Silent Aircraft," AIAA Paper 2007-0231, 2007.

${ }^{41}$ Dobrzynski, W.M., Schoning, B., Chow, L.C., Wood, C., Smith, M., and Seror, C., "Design and Testing of Low Noise Landing Gears," AIAA Paper 2005-3008, 2005.

${ }^{42}$ Dobrzynski, W., Chow, L.C., Smith, M., Boillot, A., Dereure, O., and Molin, N., "Experimental Assessment of Low Noise Landing Gear Component Design,” AIAA Paper 2009-3276, 2009.

${ }^{43}$ Khorrami, M., private communication, 2009, updated 2012.

${ }^{44}$ Jones, M.J., private communication, 2010. 